\title{
Reviews
}

\section{Genetic control of autoimmunity in Type I diabetes and associated disorders}

\author{
M. J. Redondo, G. S. Eisenbarth \\ Barbara Davis Center for Childhood Diabetes, University of Colorado Health Sciences Center, Denver, Colorado, USA
}

\begin{abstract}
Type I (insulin-dependent) diabetes mellitus is a heterogeneous disease with major subdivisions termed Type 1A (immune-mediated) and Type 1B. Immunemediated diabetes is also heterogeneous with "monogenic", oligogenic, and polygenic forms present in humans and in animal models. Single-gene mutations of two transcription factors have been recently identified in rare syndromes of autoimmunity with type 1A diabetes: autoimmune polyendocrine syndrome type 1 (APS-1) and X-linked polyendocrinopathy, immune dysfunction and diarrhoea (XPID). For more common forms of diabetes, susceptibility loci within the major histocompatibility complex and at the insulin locus have been identified. Both $\mathrm{DQ}^{*}$ and DR* alleles provide susceptibility and certain alleles dominant protection. In the Diabetes Autoimmunity Study of the Young approximately $50 \%$ of the siblings studied with the highest-risk HLA genotype develop anti-islet autoantibodies by age 3 . Insu-
\end{abstract}

lin could be a crucial autoantigen related to genetic susceptibility. The crystal structure of the high-risk allele, HLA-DQ8, complexed with an insulin peptide has just been reported. Insulin production by macrophage-dendritic cells within the thymus and lymphoid organs could underlie insulin gene polymorphisms influencing the risk of diabetes. Genome-wide scans for linkage in animal models and in humans have not conclusively identified other susceptibility genes though many loci have been implicated. We favour the hypothesis that HLA is a major determinant of susceptibility in animal models and in most families, and that the search for diabetogenes should concentrate on unique families to decrease heterogeneity and favour the eventual discovery of genes influencing risk. [Diabetologia (2002) 45:605-622]

Keywords Type I diabetes, genetics, autoimmunity, HLA, insulin gene, islet autoantibodies, autoimmune polyendocrine syndrome, XPID.
Received: 18 June 2001 and in revised form: 17 December 2001

Corresponding author: G.S. Eisenbarth, MD, PhD, Barbara Davis Center for Childhood Diabetes, University of Colorado Health Sciences Center, Box B140, 4200 East 9th Avenue, Denver, CO 80262, USA, e-mail: george.eisenbarth@uchsc.e$\mathrm{du}$

Abbreviations: APS, Autoimmune polyendocrine syndrome Type 1; XPID, X-linked polyendocrinopathy, immune dysfunction and diarrhoea; DAISY, Diabetes Autoimmunity Study of the Young; Poly-IC polyinosinic, polycytidylic acid; ICA, islet cytoplasmic autoantibody; DPT, Diabetes Prevention Trial; FPIR, first phase of insulin release; IAA, insulin autoantibodies; SSO, sequence specific oligonucleotide; HBDI, human biological data interchange; TDT, transmission disequilibrium test; NODIAB, Norwegian Diabetes study; SNP, single nucleotide polymorphism; MICA, major histocompatibility complex class I chain-related gene; ACA, adrenal cortex autoantibodies; SMS, stiff-man syndrome; VNTR, variable number of tandem repeats; ICA 512 islet cell antigen 512; CTLA-4, cytotoxic T lymphocyte antigen; LRP5, low-density lipoprotein receptor related protein 5; BDA, British Diabetes Association; APECED, autoimmune polyendocrinopathy-candidiasis-ectodermal dystrophy; AIRE, autoimmune regulator; XLAAD, Xlinked autoimmunity-allergic disregulation syndrome; XLAID, X-linked autoimmunity-immunodeficiency syndrome; Th, T cell helper; WASP, Wiskott Aldrich protein; FKH, fork head homology domain 


\section{Introduction}

Type 1A (insulin-dependent) diabetes mellitus is a relatively common autoimmune disorder with as many as 1 out of 300 children affected. Of new cases of Type $1 \mathrm{~A}$ diabetes $85 \%$ are sporadic, occurring in individuals without a first-degree relative with the disease. However, first-degree relatives of patients with type $1 \mathrm{~A}$ diabetes are at increased risk of developing diabetes, compared to the general population, suggesting that genetic factors are important in the aetiology of type $1 \mathrm{~A}$ diabetes. The risk of type $1 \mathrm{~A}$ diabetes in the general population is $0.4 \%$ and the risk for siblings of affected individuals is approximately $6 \%$. The familial clustering (lambda-s), which is defined as the ratio of the risk for siblings divided by the prevalence in the general population $[1,2]$ is approximately 15 for type $1 \mathrm{~A}$ diabetes. The offspring of a mother with type $1 \mathrm{~A}$ diabetes has a 1.3 to $4 \%$ risk of developing type $1 \mathrm{~A}$ diabetes. The risk for the offspring of a father with type $1 \mathrm{~A}$ diabetes is approximately 6 to $9 \%[3,4,5]$.

In populations with a high-incidence of type $1 \mathrm{~A}$ diabetes there is a bias in male incidence, which seems to be restricted to patients who bear HLA DR3-X, with X being "non-DR4" [6]. A recent Belgian study however, found that this male bias is age-dependent, is not present in diagnosed patients younger than 15 years of age, and is independent of the presence of anti-islet autoantibodies or HLA type, suggesting that insulin resistance can play a role. [7].

Twin studies are an important tool in defining the role of genetic and environmental factors in the aetiology of disease $[8,9,10]$. Monozygotic (identical) twins share all the genes coded in the germ line (i.e. inherited) while dizygotic (fraternal) twins share on average half of their genes, as do siblings. Differences between monozygotic twins can be due to environmental factors, to genetic factors not coded in the germ line (e.g. somatic mutations), to genes that undergo random rearrangement such as immunoglobulin and T-cell receptor genes, and to "random" monoallelic expression of genes (e.g. cytokine genes). A higher concordance rate (with both twins affected) in monozygotic than dizygotic twins suggests a primary genetic component to the aetiology of disease. Reported concordance rates for type 1A diabetes among dizygotic twins range between $0 \%$ [11] and $13 \%[12,13,14]$ and among monozygotic twins between $21 \%$ and $70 \% .[15,11,16,14]$. The prevalence of anti-islet autoantibodies in non-diabetic monozygotic twins of patients with type $1 \mathrm{~A}$ diabetes ranges between $42 \%$ and $76 \%[15,11,17]$. The presence of islet autoantibodies in a monozygotic twin of a patient with type $1 \mathrm{~A}$ diabetes is usually followed by progression to diabetes $[15,11]$.

We analysed anti-islet autoantibody expression in non-diabetic monozygotic twins, dizygotic twins, and

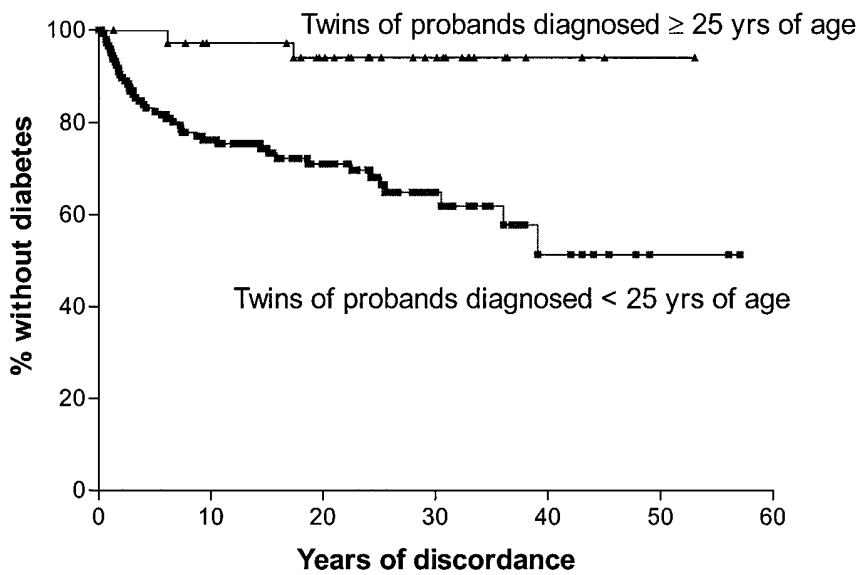

Fig.1. Development of Type 1A diabetes in initially discordant monozygotic twins of patients subdivided by the age of diabetes onset in the proband twin

siblings of patients with type 1A diabetes [14]. Consistent with other studies [18, 19], monozygotic twins had a much higher risk of progressing to diabetes and expressing autoantibodies than the dizygotic twins. There was a higher penetrance of anti-islet autoimmunity in monozygotic twins who were heterozygous for the two high-risk HLA haplotypes DQ2 and DQ8. In a combined series of 187 monozygotic twins from Britain and the United States [20], we could also confirm that diabetes risk was higher in twins who were heterozygous for DR3-DQ2 and DR4-DQ8 than in twins with neither DR3-DQ2 nor DR4-DQ8. In this combined series, the hazard rate of progression to diabetes was higher within 10 years from diagnosis in the index twin [21]. However, $23 \%$ of the twins who became diabetic did so after more than 15 years of discordance as shown in our previous studies [15]. In addition we observed a higher progression rate to diabetes for twins whose index twin developed diabetes at a younger age (Fig. 1). Progression to diabetes was estimated to be $38 \%$ $(\mathrm{SEM}=5.3 \%)$ by 30 years of discordance for the twins of index cases who were diagnosed with diabetes at a younger age than 25, compared to $6 \%$ $(\mathrm{SEM}=4.1 \%)$ for the co-twins of index twins diagnosed at 25 years of age or older. Twins of patients who were diagnosed at age 9 or younger have an estimated $50 \%$ risk of developing type $1 \mathrm{~A}$ diabetes within 6 years.

There are also a relatively large number of spontaneous animal models of type $1 \mathrm{~A}$ diabetes suggesting that islets are particularly susceptible to immunemediated destruction. Oligogenic animal models of type $1 \mathrm{~A}$ diabetes include the BB rat and the Tokushima rat, both of which have the same major histocompatibility (MHC) set of alleles, termed RT1-U [22, 23, 24]. RT1-U, alleles and in particular class II alleles, are important susceptibility factors, with homozygosity for the $U$ haplotype conferring the greatest sus- 


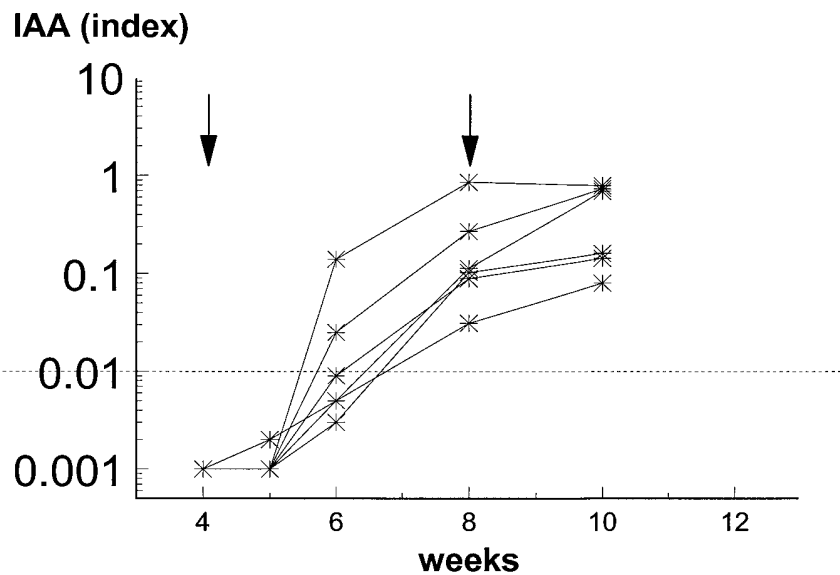

Fig. 2. Peptide-specific induction of IAA with B9-23 peptide in $\mathrm{BALB} / \mathrm{c}$ mice. Black arrows indicate the time of immunisation with peptide

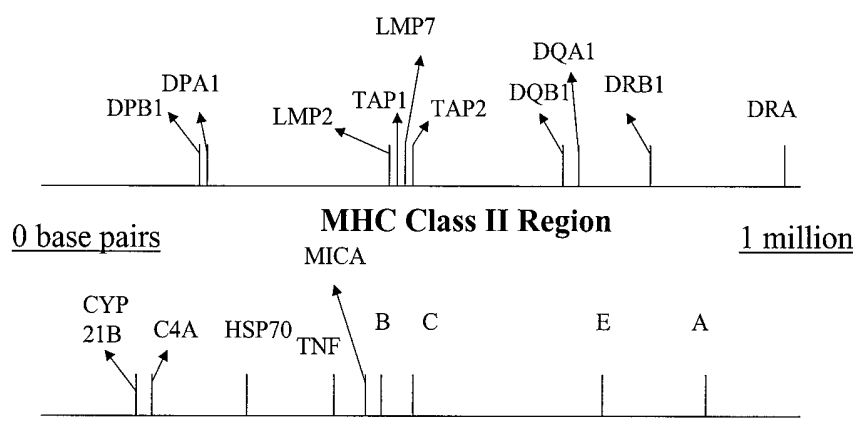

1 million Class III Region

Class I Region

4 million

Fig.3. The major histocompatibility complex, on chromosome 6

ceptibility. Of note, many rat strains with RT1-U can be induced to develop insulitis or diabetes simply by activating the immune system using poly-IC (polyinosinic, polycytidylic acid) [25]. Poly-IC activates the innate immune system through toll receptors generating interferon- $\alpha$ and is thought to be a mimic of viral RNA. It is likely that Kilham rat virus infection acts in a similar manner to induce diabetes in the $\mathrm{BB}$ rat strain (BB-DP) that lacks the lymphopenia gene [26].

More than 40 years ago investigators produced severe insulitis (and occasionally diabetes) in rabbits immunised with insulin or in cows immunised with bovine insulin. We have recently been able to produce anti-insulin autoantibodies in normal Balb/c mice immunising with an immunodominant peptide of insulin (peptide B:9-23) and with B:9-23 in combination with poly-IC insulitis (Fig. 2) [27]. Disease induction again was critically dependent upon specific MHC alleles, in this case I-Ad or the related I-Ag7 of the NOD spontaneous mouse model of diabetes. Thus given the "right" (wrong) MHC alleles it seems that susceptibility to anti-islet autoimmunity is common.
For most "complex" genetic disorders discovery of a locus with an influence as strong as the HLA locus would be a major finding. The HLA locus accounts for approximately half of the familial aggregation of type 1A diabetes. Approximately two percent of newborns in Colorado have the HLA DQ* genotype DQ2-DQ8 (DQA1*0501, DQB1*0201;DQA1*0301, DQB1*0302) and comprise almost $50 \%$ of children developing diabetes before age 5. Given such a major locus the discovery of additional loci is likely to be difficult, especially if there are several or many additional loci. The most dramatic recent advances in our understanding of the genetics of type $1 \mathrm{~A}$ diabetes relates to the discovery of rare specific mutations leading to autoimmunity with associated diabetes.

\section{IDDM1: HLA}

\section{Type $1 A$ diabetes without associated autoimmunity}

MHC genes explain approximately $50 \%$ of the familial aggregation of type $1 \mathrm{~A}$ diabetes. Nerup and coworkers initially reported the association between HLA alleles and type $1 \mathrm{~A}$ diabetes more than 20 years ago [28]. The association between polyglandular failure syndrome type 2 , which includes type $1 \mathrm{~A}$ diabetes, and HLA (Fig.3), specifically HLA-B8, was also recognized long ago [29]. The class II HLA alleles DR4 and DR3 are strongly associated with type $1 \mathrm{~A}$ diabetes. Part of this association is probably secondary to linkage disequilibrium (non-random association of alleles on the same haplotype) between $\mathrm{DR}^{*}$ and $\mathrm{DQ}^{*}[30,31]$. DQA1*0301-DQB1*0302 (also called DQ8) with HLA DRB1*0401, *0402 or *0405 alleles and HLA DRB1*0301-DQA1*0501DQB1*0201 (also called DQ2) are the haplotypes associated with the highest risk for diabetes. Ninety percent of individuals with type $1 \mathrm{~A}$ diabetes have at least one of these two high-risk HLA haplotypes compared to $20 \%$ of the general population. Approximately $35 \%$ of patients in the United States with type 1A diabetes are "DR3-DR4" heterozygous compared with only $2.4 \%$ of the general population. The risk of developing anti-islet autoantibodies is also increased among first-degree relatives of patients with diabetes with the HLA-DR4-DQ8 haplotype $[32,33]$.

Approximately, $50 \%$ of the children who develop type $1 \mathrm{~A}$ diabetes at an age younger than 5 years have both high-risk haplotypes, DR3-DQ2 and DR4-DQ8 (M. Rewers, personal communication). Overall siblings of a patient with type 1A diabetes have a risk of diabetes of approximately $6 \%$. However, for siblings who inherited the same HLA haplotypes as a sibling with type $1 \mathrm{~A}$ diabetes, the estimated risk increases to $20 \%$. In the Diabetes Autoimmunity Study of the Young (DAISY) approximately one half 
Table 1. HLA alleles associated with protection from type 1A diabetes

\begin{tabular}{lcc}
\hline DQA1* & DQB1* & DRB1* \\
\hline Strong protection & & \\
0102 & 0602 & 1501 \\
0101 & 0503 & 1401 \\
0201 & 0303 & 0701 \\
\multicolumn{2}{l}{ Weak or moderate protection } & \\
0301 & 0302 & 0403 \\
0201 & 0201 & 0701 \\
0501 & 0301 & 1101 \\
\hline
\end{tabular}

Adapted from G.S. Eisenbarth, "Genetic Basis of Autoimmune Diabetes", in Metabolic Basis of Common Inherited Diseases. Eds. G. Williams and J.F. Habener. W. B. Saunders Company. Copyright (2000) WB Saunders Company

of siblings with the genotype DR3-4, DQ2-8 develop anti-islet autoantibodies by age 3 and are at a high risk of diabetes. Offspring with the same genotype have a risk of $25 \%$.

The risk conferred by the DQ8 molecule is modified by the DRB1 allele present on the same haplotype. The DRB1*0402,*0401 and *0405 alleles are associated with high susceptibility, the DRB1*0404 with moderate susceptibility, and DRB $1 * 0403$ with "protection" against type 1A diabetes [30]. DRB1*0401 is the strongest susceptibility allele in most Caucasian populations, whereas DRB1*0402 and $* 0405$ seem to be more important in Mediterranean populations and Israeli populations [34]. A Yemenite Jewish population apparently had almost no development of type 1A diabetes in Yemen but now has one of the highest risks in the world, with essentially all patients having the genotype DR3-4, DQ2-8 [34].

The DQA $1 * 0301$ allele frequently found on DR4 haplotypes, as well as *0101, *0102,*0103 and *020 (lineage 1-3 DQA1 alleles) are associated with high concentrations of insulin autoantibodies [35].

Some HLA alleles confer protection from diabetes (Table 1) [33, 36].

The best-known protective allele is DQB1*0602, usually found on "DR2" (DRB1*1501-DQA1*0102DQB1*0602) haplotypes. Approximately $20 \%$ of North Americans and Europeans have DQA1*0102DQB1*0602 while less than $1 \%$ of children with type 1A diabetes carries these alleles. The protection conferred by the DQA1*0102-DQB1*0602 haplotype seems to be dominant since it is protective even in the presence of a high-risk haplotype in the same individual [33]. The protective effect of the DQB1*0602 allele is likely to occur both before and after the autoimmune destruction of the pancreas is in progress. Among first-degree relatives of patients with diabetes, the allele DQB $1 * 0602$ is present in approximately $7 \%$ of islet cytoplasmic autoantibody (ICA)-positive relatives. The frequency of the
DQB1*0602 allele was similar among 72 ICA-positive first-degree relatives and 126 first-degree relatives who were autoantibody-negative. However, progression to diabetes is rare in relatives who are positive for this allele, especially for those expressing only a single anti-islet autoantibody [33]. First-degree relatives with positive ICA and the DQB1*0602 allele had a more limited response to islet antigens, often directed to GAD, compared to ICA-positive, 0602-negative first-degree relatives $[37,38]$. In a further study, a restricted pattern of ICA staining and high titres of GAD65 autoantibodies was found in autoantibody-positive 0602-positive patients who did not develop diabetes [39]. Among individuals identified through the Diabetes Prevention Trial (DPT), 0602-positive individuals were less likely to have positive insulin autoantibodies or a "low" first phase of insulin release (FPIR) compared to relatives without DQB1*0602. Although $29 \%$ of the ICA-positive 0602-positive relatives did have insulin autoantibodies or "low" FPIR [40], approximately $15 \%$ of ICA negative relatives were IAA positive based on the polyethylene-glycol based assay used in the study, and low FPIR for adults was defined as less than the 10 th percentile.

The presence of DQB $1 * 0602$ also protects from diabetes patients with stiff-man syndrome, who are otherwise at increased risk for type 1A diabetes. Of note, this syndrome is associated with extremely high values of GAD autoantibodies [41]. Four patients with type $1 \mathrm{~A}$ diabetes who were initially found to have the conventional DQB1*0602 with standard sequence-specific oligonucleotide (SSO) typing techniques were reported to actually have novel variants of this allele as determined by sequencing [42]. This finding would suggest that the conventional DQA1*0102-DQB1*0602 haplotype is never found in patients with type $1 \mathrm{~A}$ diabetes and that this haplotype confers absolute protection from the disease. We have however, documented eight non-diabetic ICA-positive first degree relatives and six patients with type $1 \mathrm{~A}$ diabetes who carry the DQA1*0102DQB1*0602 haplotype by standard SSO technique typing and the conventional second exon of DQB1*0602 and DQA1*0102 alleles by direct sequencing [43]. Therefore, type 1A diabetes can develop in individuals carrying the DQB $1 * 0602$ allele, and the protective effect associated with this allele is not absolute. The protective effect of DQB $1 * 0602$ could differ among ethnic groups. African-American ICApositive relatives were more likely to carry the DQA1*0102-DQB1*0602 haplotype than other ethnic groups. Hispanic ICA-positive relatives with DQB1*0602 were more likely to have positive insulin autoantibodies or to have low FPIR than other racial groups [40].

Protection from diabetes conferred by the DR2-DRB1*1501-DQA1*0102-DQB1*0602 haplo- 
type seems to be an effect of the DQ molecule. An unusual DQB1 allele was found by sequence analysis on the DR2 haplotype in three siblings with type 1A diabetes [44]. The DRB1 allele on these DR2 haplotypes was the conventional allele $(* 1501)$. In a recent study of 1371 subjects from the Human Biological Data Interchange (HBDI) type 1A diabetes repository and 2441 subjects from the Norwegian NODIAB study, DQA1*0102-DQB1*0602 haplotypes were infrequently (2/313) transmitted to diabetic offspring, while rare DRB1*1501 haplotypes without DQA1*0102-DQB1*0602 were transmitted to 5 out of 11 affected offspring [45]. This finding further supports the hypothesis that the protection associated with the DQA1*0102-DQB1*0602 haplotype is an effect of the $\mathrm{DQ}^{*}$ alleles rather than the DRB1*1501, which is in linkage disequilibrium with DQ* alleles. Of interest, the presence of serum heterophile antibodies (i.e. antibodies that can bind animal immunoglobulins and interfere with analyte quantification by immunoassay) was associated with the protective allele DQB1*0602 [46, 47].

Uncommon HLA alleles can also have an effect on diabetes risk or protection. Transmission of DQ haplotypes from heterozygous parents to affected and unaffected offspring was analysed in 276 families from the Human Biological Data Interchange (HBDI) type $1 \mathrm{~A}$ repository. Over $95 \%$ of the HBDI families are multiplex families, ascertained as having two or more affected siblings. The transmission disequilibrium test (TDT) [48] was used to help distinguish between association due to linkage and spurious association due to population stratification. The rank order of transmission to affected offspring was DQA1*0301-DQB1*0302 (associated with the highest risk), DQA1*0501-DQB1*0201, DQA1*0401DQB1*0402 and DQA1*0101-DQB1*0501. The DQ haplotype that was least often transmitted to affected offspring was the well-known protective haplotype DQA1*0102-DQB1*0602, followed by DQA1*0103DQB1*0603 [49].

DQA1*0101-DQB1*0503 is a rare haplotype, present only in $1.6 \%$ of haplotypes in North America [50], that also confers protection from type $1 \mathrm{~A}$ diabetes. Large study populations are needed to analyse the protection or risk associated with uncommon alleles. We used the transmission disequilibrium test analysis to analyse transmission of uncommon alleles from heterozygous parents to affected and unaffected offspring within families in the HBDI (1371 subjects) and NODIAB studies (2,441 subjects). The DQA1*0101-DQB1*0503 was transmitted from heterozygous parents to affected offspring only 2 out of 42 times. In an additional case-control analysis of 728 patients with type $1 \mathrm{~A}$ diabetes and 110 healthy control subjects from the Barbara Davis Center, we could confirm a protective effect of this haplotype, in agreement with previous reports [51]. The only two affected offspring who inherited these $\mathrm{DQ}^{*}$ alleles in our combined family study did not have the DRB1*1401 allele usually found on the same haplotype with DQB1*0503, while all non-affected children who inherited DQA1*0101-DQB1*0503 had DRB1*1401. Among the three patients with type 1A diabetes from the Barbara Davis Center who had DQB1*0503, only one had DRB1*1401.

It is not yet known whether the association between HLA alleles or haplotypes and protection or risk of diabetes is due to pleiotropic effects of specific alleles or haplotypes, or to linkage disequilibrium with a nearby sequence. In contrast, the reported association between polymorphisms in the heat-shock protein genes located within the MHC and type 1A diabetes is believed to be due to linkage disequilibrium of alleles on extended haplotypes associated with diabetes [52]. Similarly, tumour necrosis factor microsatellite haplotype associations with Type I diabetes and multiple sclerosis have been attributed to the known associations of these diseases with extended haplotypes [53].

\section{Mechanisms of diabetogenicity of HLA molecules}

The influence of HLA molecules on diabetes susceptibility or protection can be related to their ability to present peptides to T cells. Central tolerance is the process that allows HLA molecules present self-peptides to naive T-cells in the thymus so that tolerance is developed. Inefficiency of specific HLA types to facilitate this could contribute to autoimmunity. Alternatively, or in addition to the loss of central tolerance, abnormalities of peripheral tolerance can be present, with some HLA alleles presenting specific peptides (such as islet cell peptides) to mature T lymphocytes that did not undergo negative selection. A number of investigators have advanced the hypothesis that HLA alleles associated with susceptibility to autoimmunity could be "unstable" $[54,55,56]$. Though this hypothesis is feasible it is difficult to reconcile with the same HLA haplotypes associated with protection from diabetes and susceptibility for multiple sclerosis (e.g. DR2, DQB1*0602) or with the strong binding of insulin peptide B:9-23 to DQ8 whose crystal structure has recently been solved [57].

Conformational properties of the HLA molecule can determine that the binding between the peptide and the T cell will never allow the peptide to be effectively presented to the T cells. Inter-ethnic group studies support the hypothesis of conformational structure influencing diabetogenicity of some HLA alleles or haplotypes. For instance, among the Japanese, the DQB1*0401 allele is usually found on DR4DQA1*0301-DQB1*0401 haplotypes and is associated with diabetes risk [58]. The DQB1*0401 and DQB1*0402 alleles differ only by one amino acid. 
Among Norwegians, the heterozygous DQA1*0301DQB1*0302/DQA1*0401-DQB1*0402 genotype appears to be associated with type $1 \mathrm{~A}$ diabetes. A very similar molecule could be formed among Japanese in cis (DR4-DQA1*0301-DQB1*0401) and among Norwegians in trans (DQA1*0301- DQB1*0402).

The presence of an aspartic acid at position 57 of the DQ beta chain was hypothesized to be associated with the prevention of diabetes [59] since it is present in DQA1*0102-DQB1*0602 and absent in DQB1*0302 and DQB1*0201. Similarly, the presence of an arginine at position 52 of the DQ alpha chain was believed to determine susceptibility to type $1 \mathrm{~A}$ diabetes since it is present on the DQA $1 * 0301$ DQB1*0302 and DQA1*0501-DQB1*0201 haplotypes. However, the high-risk haplotypes DQA1*0401-DQB1*0402 and the DQA1*0301 and DQB1*0401 alleles have an aspartic acid at position 57 of the DQ beta chain, as do the moderate-risk alleles DQB1*0301 and DQB1*0303 alleles.

Transgenic mice expressing human DQ8 with beta-cell expression of the co-stimulatory molecule B7-1 develop type 1A diabetes indicating a direct positive diabetogenic effect of DQ8 [60]. The only class II allele expressed by the NOD mouse is the diabetogenic I-Ag7 molecule. Crystal structure analysis of this molecule showed a "normal" class II binding cleft with a large pocket and the ability to bind multiple peptides [61]. The structure of a peptide mimotope that elicits the preferential expansion of beta-reactive $T$ cells in NOD mice has been defined [62]. A mouse with a transgene encoding a "diabetogenic" T-cell receptor is protected from diabetes by multiple "deleting" class II alleles providing a mechanism for dominant protection [63].

We suspect that class I and class II alleles influence diabetes susceptibility both by the T-cell receptors, which are being deleted centrally, and also by the specific peptides present in the periphery [64]. This hypothesis is consistent with the observation that HLA haplotypes with identical $\mathrm{DR}^{*}$ and $\mathrm{DQ}^{*}$ alleles have a similar effect on disease risk in different populations (e.g. Korea and USA) [65].

\section{Non-DQ*/DR* genes within the HLA region}

Non-DQ*-DR* genes within the HLA region might also have an effect on diabetes risk. Using a conditional linkage disequilibrium analysis association test, alleles of single nucleotide polymorphisms (SNPs) at the DMB and DOB genes, and microsatellite alleles of TNFc, identified approximately $40 \%$ of DR3 haplotypes as non-predisposing in the founder population of Sardinia [66].

The major histocompatibility complex class I chain-related (MICA) gene is located in the short arm of chromosome 6 , within the HLA region
(Fig.3). The transmission disequilibrium test was used to study transmission to patients with type 1A diabetes of polymorphisms in exon 5. A microsatellite allele consisting of six repetitions of GCT-AGC (A6) and an allele with four repetitions (A4) were analysed. The A6 polymorphism was transmitted at a lower than expected frequency and the A4 polymorphism was transmitted at a higher than expected frequency [67].

When evaluating haplotypes of HLA alleles, the influence on diabetes risk could be provided by a combination of alleles of known class I molecules rather than by unknown "new" genes influencing diabetes risk. This will be particularly difficult to distinguish for what have been termed "ancestral" or "extended" HLA haplotypes such as the very conserved A1, B8, DR3, DQ2 haplotype $[68,69,70]$.

\section{Type 1 A diabetes with associated autoimmunity}

Individuals with type $1 \mathrm{~A}$ diabetes are at increased risk for other diseases, particularly autoimmune disorders. Most dramatic are the autoimmune polyendocrine syndromes type 1 (APS-1) and type 2 (APS-2). In APS- 1 there is a mutation in the AIRE gene encoding a protein whose structure suggests that it is a transcription factor. It has been hypothesized that AIRE protein can be critical for thymic stromal organisation and induction of self-tolerance. APS-2, also known as Schmidt's syndrome, is much more common than APS-1. APS-2 patients frequently have at least two of the three following disorders: Addison's disease, autoimmune thyroid disease, and type 1A diabetes. Other conditions that can be present include celiac disease, autoimmune hepatitis, gonadal failure, vitiligo, alopecia, pernicious anaemia, myasthenia gravis and a number of less common disorders [71]. APS-2 usually presents in early adulthood with a peak onset at 30 years of age. This syndrome is three times more common in females than males, and the female to male ratio is higher for specific disorders, e. g. Grave's disease, with a 7:1 ratio. Most of the genetic susceptibility for APS-2 is accounted for by HLA alleles [29, 72, 73, 74]. APS-2 is associated with DQA1*0501, DQB1*0201 (DQ2) [75] and because of linkage disequilibrium (non-random association), with A1, B8 and DR3 [75]. The HLA-association of the APS-2 is also found with individual disorders, such as Addison's disease and type 1A diabetes, when they appear as isolated conditions without evidence of other disorders of the syndrome [76].

Addison's disease is a condition characterized by failure of the adrenal gland that leads to fatigue, hyperpigmentation of the skin, abdominal pain, dehydration, low blood pressure, cardiovascular shock and, if untreated, death. Autoimmune destruction of the adrenal gland is the most common cause of Addi- 
son's disease in developed countries, whereas infection by Mycobacterium tuberculosis is more common in other settings. Adrenal cortex autoantibodies (ACA) are found in 43 to $84 \%[77,78]$ of patients with idiopathic adrenal failure. The major target of ACA is the steroidogenic enzyme P450c21 (21-hydroxylase). Autoantibodies against 21-hydroxylase have been documented in over $90 \%$ of patients with Addison's disease [79] and have not been found in non-autoimmune adrenal insufficiency and other conditions or in healthy control subjects. Approximately $1.5 \%$ of patients with type $1 \mathrm{~A}$ diabetes are positive for 21-hydroxylase autoantibodies.

Among patients with Addison's disease, over $80 \%$ with DR4 have the DRB1 allele, DRB1*0404, usually in linkage disequilibrium with DR4-DQA1*0301, DQB1*0302. Approximately 30 to $50 \%$ of the patients with Addison's disease have the genotype DRB1*0404, DQA1*0301, DQB1*0302 with DRB1*0301, DQA1*0501, DQB1*0201, which is found only in 1 out of 200 newborns in the general population (Denver, Colorado) and in $11 \%$ of patients with type 1A diabetes without Addison's disease [80].

Type 1A diabetes is associated with DRB1*0401, 0402 and 0404, while Addison's disease is primarily associated with DRB1*0404 [80]. Both Addison's disease and type $1 \mathrm{~A}$ diabetes share a high risk genotype (DR3/DR4. DRB1*0404, increases the risk that an individual will develop Addison's disease and decreases modestly the risk of Type I diabetes (relative to DRB1*0401). Approximately 1 out of 20 patients with DR3-4, DQ2-DQ8 and type 1A diabetes have anti-adrenal 21-hydroxylase (e.g. 10/208) autoantibodies [81] compared to less than $0.5 \%$ of patients with type 1A diabetes who have neither DQ8 nor DQ2. Among 21-hydroxylase autoantibody positive diabetic patients with DQA1*0301-DQB1*0302, 80\% (12/ $15)$ of patients with DRB1*0404 had Addison's disease in contrast to $10 \%(1 / 10)$ of 21-hydroxylase autoantibody-positive patients who had other DRB1 alleles (DRB1*0401 or DRB1*0402) [80].

Patients with type $1 \mathrm{~A}$ diabetes also have an increased risk of celiac disease. This is an autoimmune disorder associated with characteristic intestinal lesions that occur with the ingestion of gliadin, a glutamine-rich protein present in wheat, rye and barley. Typically the lesions disappear rapidly when this protein is removed from the diet. This disorder occurs in 0.5 to $1 \%$ of children from the general population as documented in studies from Europe and in the United States DAISY study. In the DAISY study infants were followed from birth for the development of transglutaminase autoantibodies and then biopsied to diagnose celiac disease if autoantibodies were present. Transglutaminase autoantibodies are highly predictive of celiac disease, with most patients (13/ 13) with an index greater than 0.7 having a positive intestinal biopsy [82]. Celiac disease is strongly asso- ciated with the DQA1*0501-DQB1*0201 (DQ2) haplotype. This heterodimer can be encoded in either cis, usually with a DR3 haplotype, or in trans, with DR7-DQA1*0201-DQB1*0201 on one chromosome and DR5-DQA1*0501-DQB1*0301 on the other chromosome [83]. Approximately 1 out of 3 patients with type 1A diabetes who are DQ2 homozygous express transglutaminase autoantibodies, and half of these have celiac disease on biopsy [82]. In a group of asymptomatic children screened because of a genetic risk (such as a family history of Type I diabetes or high-risk HLA types), transglutaminase antibodies had a positive predictive value of $70 \%$ to $83 \%$ for celiac disease evident on biopsy [83].

Stiff-man syndrome (SMS) is a rare neurologic disorder characterized by rigidity of the body musculature, with spasms triggered by sensory or emotional stimuli, with a characteristic electromyography pattern. Autoantibodies against glutamic acid decarboxylase (GAD) are found in the serum and cerebrospinal fluid of $60 \%$ of patients with SMS. SMS is also associated with the haplotype DR3, DQA1*0501,DQB1*0201 [84].

\section{IDDM2: insulin gene}

The IDDM2 locus, on chromosome 11p15, includes a variable number of tandem repeats (VNTR) minisatellite 5' of the insulin gene. Polymorphisms in this non-coding region of the insulin gene (INS) are associated with the risk of diabetes and influence thymic insulin messenger RNA [85, 86, 87]. There are three main types of the insulin VNTR defined by their size: class I (26-63 repeats), class II (approximately 80 repeats) and class III (140-200 repeats). Each one of them can be further divided based on the number of repeats and sequence.

The presence of "peripheral antigen expressing cells" within the thymus have been described [88, 89]. Allelic variation in the size of the insulin VNTR correlates with the expression of insulin in the pancreas and thymus and with placental expression of insulin growth factor-2 gene (IGF-2), which is downstream from the insulin gene [90].

Homozygosity for class I alleles is associated with high risk for diabetes, whereas class III alleles confer dominant protection. Class III alleles are associated with higher expression of insulin messenger RNA within the thymus, and insulin with thymic transcription activity correlate inversely with susceptibility in humans and in transgenic models [91]. These findings support the hypothesis that genetically-determined differences in the expression of self-antigens in the thymus could influence susceptibility to autoimmunity. High concentration of thymic insulin might lead to negative selection (deletion) of autoreactive $\mathrm{T}$ cells bearing a TCR that is directed against self-anti- 
gens and thus to the development of tolerance. Alternatively, higher expression could favour the development of insulin-peptide-responsive T regulatory cells.

The IA-2 islet autoantigen was identified as an "insulinoma-associated tyrosine phosphatase-like protein" and from screening islet libraries with autoantibodies [islet cell antigen 512 (ICA 512)]. Islets express full-length mRNA for IA-2 and two alternatively spliced transcripts, whereas thymus and spleen exclusively express an alternatively spliced transcript lacking exon 13. Exon 13 encodes the transmembrane and juxta-membrane domains of IA-2. Thus, tolerance cannot be achieved for the IA-2 epitopes expressed in islets but not in lymphoid organs [92]. A novel subset of peripheral antigen-expressing cells which synthesize (pro)insulin, GAD and IA-2 has been described [93]. These cells are found in the thymic medulla, spleen and lymph nodes, and can be surrounded by apoptotic lymphocytes. Therefore, they might play a role in the deletion of self-reactive lymphocytes.

A parent-of-origin effect has been described for IDDM2, with alleles being protective when paternally inherited $[94,95]$. Imprinted paternal expression of INS in the human yolk sac has been described [90].

\section{IDDM3 to IDDM18}

Multiple loci, in addition to HLA and the insulin gene, have been associated with the risk of diabetes. Most of the additional loci were discovered by analysis of sibling pairs with Type I diabetes. Some of these loci were reported in a single population and could not be confirmed outside of it. Putative IDDM loci with their chromosomal localization and candidate genes in that region are summarized (Table 2). For some of these loci, such as D2S137 or D14S67, the association seems to be stronger in patients lacking the high risk HLA alleles, DQ2 or DQ8 [96, 97]. Some studies have found that age of diagnosis, sex of affected subjects, and parental origin of shared alleles modify the influence of loci on diabetes risk [98, 99]. Studies of the IDDM12 locus (CTLA-4 associated) illustrate the heterogeneity of disease associations and IDDM17 identification of the locus by studying a single unique family.

\section{IDDM12: cytotoxic T lymphocyte-associated antigen (CTLA-4)}

The cytotoxic $\mathrm{T}$ lymphocyte-associated antigen (CTLA-4) gene, on chromosome 2 q33, encodes a receptor expressed by activated T cells. CTLA-4 binds B7 molecules and limits the proliferative response of activated T cells, some of which could be autoreactive. Mutations or polymorphisms leading to altered activity of CTLA-4 are believed to play an important role in the risk for developing autoimmunity. CTLA4 gene polymorphisms have been associated with component disorders of the autoimmune polyglandular syndrome type 2 (e.g. Hashimoto's thyroiditis [118], Addison's disease [118], celiac disease [119], type 1A diabetes [111], and Graves' disease, [111].

In type $1 \mathrm{~A}$ diabetes, the effect of IDDM12 seems to be independent of HLA alleles or the insulin gene VNTR I/I risk genotype [120]. A A/G polymorphism in the first exon in CTLA4 results in an amino acid change (Thr/Ala). The presence of an alanine on codon 17 of CTLA 4 has been associated with susceptibility to type $1 \mathrm{~A}$ diabetes, autoimmune thyroid disease and primary biliary cirrhosis [121] but not with Type II (non-insulin-dependent) diabetes mellitus [122].

CD28 is another candidate gene in the IDDM12 region. However, transmission disequilibrium test (TDT) analyses in a multiethnic population did not show an association with CD28 [123].

Ethnic heterogeneity of the effect of IDDM12 on type 1A diabetes risk has been observed. IDDM12 has a strong effect in three Mediterranean-European populations (Italian, Spanish and French), the Mexican-American population and the Korean population, a weak transmission deviation in the Caucasian-North American, and no deviation in the British, Sardinian and Chinese populations [112]. A study in a Danish population found no association between IDDM12 and risk for type 1A diabetes [124]. The polymorphic (AT)n microsatellite in the 3' untranslated sequence of the CTLA-4 gene was reported to represent a recessive risk factor for type 1A diabetes in Swedish patients [125]. In a Russian population, the 17 allele of the human cytotoxic T lymphocyte-associated antigen-4 (CTLA4) gene was associated with diabetes, whereas the 20 and 26 alleles were protective $[126,124]$. There was no evidence that the CTLA-4 exon 1 polymorphism (49 A-G) confers genetic susceptibility to type $1 \mathrm{~A}$ diabetes mellitus in a case-control study on 117 Japanese subjects. The frequency of positive antibodies to GAD was higher in GG subjects, raising the question as to whether CTLA-4 polymorphisms contribute to the heterogeneity of type $1 \mathrm{~A}$ diabetes mellitus in Japanese subjects [127]. These differences between populations and the relatively small effects in "positive" studies limit the utility of CTLA-4 analysis.

\section{IDDM17}

The diabetes susceptibility locus (IDDM17) was mapped by genetic linkage analysis in a Bedouin Arab family with 21 patients with type $1 \mathrm{~A}$ diabetes (Fig.4). IDDM17 maps to the long arm of chromosome 10 (10q25; non-parametric linkage $=4.99$, $p=0.00004)$ and is associated with a $151 \mathrm{bp}$ allele at 
Table 2.

\begin{tabular}{|c|c|c|c|}
\hline & Locus & Candidate gene & Remarks \\
\hline IDDM1 & $6 \mathrm{p} 21.31$ & HLA & See text \\
\hline IDDM2 & $11 \mathrm{p} 15$ & Insulin gene & See text \\
\hline IDDM4 & $\begin{array}{l}\text { 11q13 } \\
\text { D11S987[102, 103] }\end{array}$ & \multirow[t]{3}{*}{$\begin{array}{l}\text { Low-density lipoprotein receptor } \\
\text { related protein } 5 \text { (LRP5) }\end{array}$} & $\begin{array}{l}\text { Protein containing conserved modules that are } \\
\text { characteristic of the LDL receptor family }\end{array}$ \\
\hline IDDM6 & 18q12-q22 D18S487 [104, 105] & & $\begin{array}{l}\text { Also associated with rheumatoid arthritis, systemic } \\
\text { lupus erythematosus and Graves' disease. } \\
\text { ZNF236, on 18q22-q23, is a candidate gene for } \\
\text { diabetic nephropathy }\end{array}$ \\
\hline IDDM7 & 2q31-q33 D2S152 [106, 102] & & $\begin{array}{l}\text { "Suggestive" LOD score (2.8) combined British } \\
\text { and USA series } 107\end{array}$ \\
\hline IDDM10 & $\begin{array}{l}10 p 11-q 11 \\
\text { D10S197 } \\
{[102,110]}\end{array}$ & \multirow{2}{*}{ CD80 and CD86 } & $\begin{array}{l}\text { "Suggestive" LOD score (2.8) combined British } \\
\text { and USA series [107] }\end{array}$ \\
\hline IDDM11 & $\begin{array}{l}14 q 24.3-q 31 \\
\text { D14S67 [96] }\end{array}$ & & $\begin{array}{l}\text { ENSA gene encodes human alpha-endosulfine, } \\
\text { an endogenous regulator of the beta cell K(ATP) } \\
\text { channels }\end{array}$ \\
\hline IDDM12 & $\begin{array}{l}\text { 2q33 } \\
\text { D2S272- CTLA4- D2S116 } \\
{[111,112]}\end{array}$ & \multirow[t]{2}{*}{ CTLA-4 } & \multirow[t]{2}{*}{ See text } \\
\hline IDDM13 & $\begin{array}{l}\text { 2q34 } \\
\text { D2S137-D2S1471 [113114] }\end{array}$ & & \\
\hline IDDM18 & $\begin{array}{l}5 \mathrm{q} 31.1-\mathrm{q} 33.1[117] \\
16 \mathrm{q} 22-24 \\
\text { D16S3098 }\end{array}$ & IL-12 p40 gene & $\begin{array}{l}\text { See text } \\
\text { LOD score } 3.93 \text { combined British and USA series } \\
{[107]}\end{array}$ \\
\hline
\end{tabular}

the microsatellite marker D10S554. Relatives in the family with HLA DR3 or DR4 plus IDDM17 have a diabetes risk of $40 \%$ [116].

Recently, we identified 107 single nucleotide polymorphisms (SNPs) within $100 \mathrm{~kb}$ on either side of D10S554. These SNPs were genotyped in a set of 45 families in the United States [Human Biologic Disease Interchange (HBDI) families] that were segregating the 151-bp allele at D10S554. In a subset of families the haplotypes that were transmitted to diabetic offspring showed remarkable similarity to the high risk haplotype (designated the ' $\mathrm{B}$ ' haplotype) found in the Bedouin Arab family [128]. With the sequence information provided by the genome project it is now possible to create detailed maps of hundreds of thousands of contiguous base pairs. Extended haplotypes should aid identification of disease related loci but can increase the difficulty of pinpointing individual "causative" polymorphisms, with multiple alleles in the block associated with disease.

\section{Other genes and loci}

Publication of the analysis of a relatively large $(>700$ families) combined series of families from the United States (HBDI) and British Diabetes Association (BDA) family collections is now available. Even this series is probably too small to provide definitive information for many loci beyond the clear confirmation of the HLA (LOD score 65) and insulin locus (LOD score 4.28). Three previously reported "iddm" loci had a LOD score greater than 2 [iddm $10(\mathrm{LOD}=2.8)$, iddm7 $(\mathrm{LOD}=2.6)$ and iddm 15 


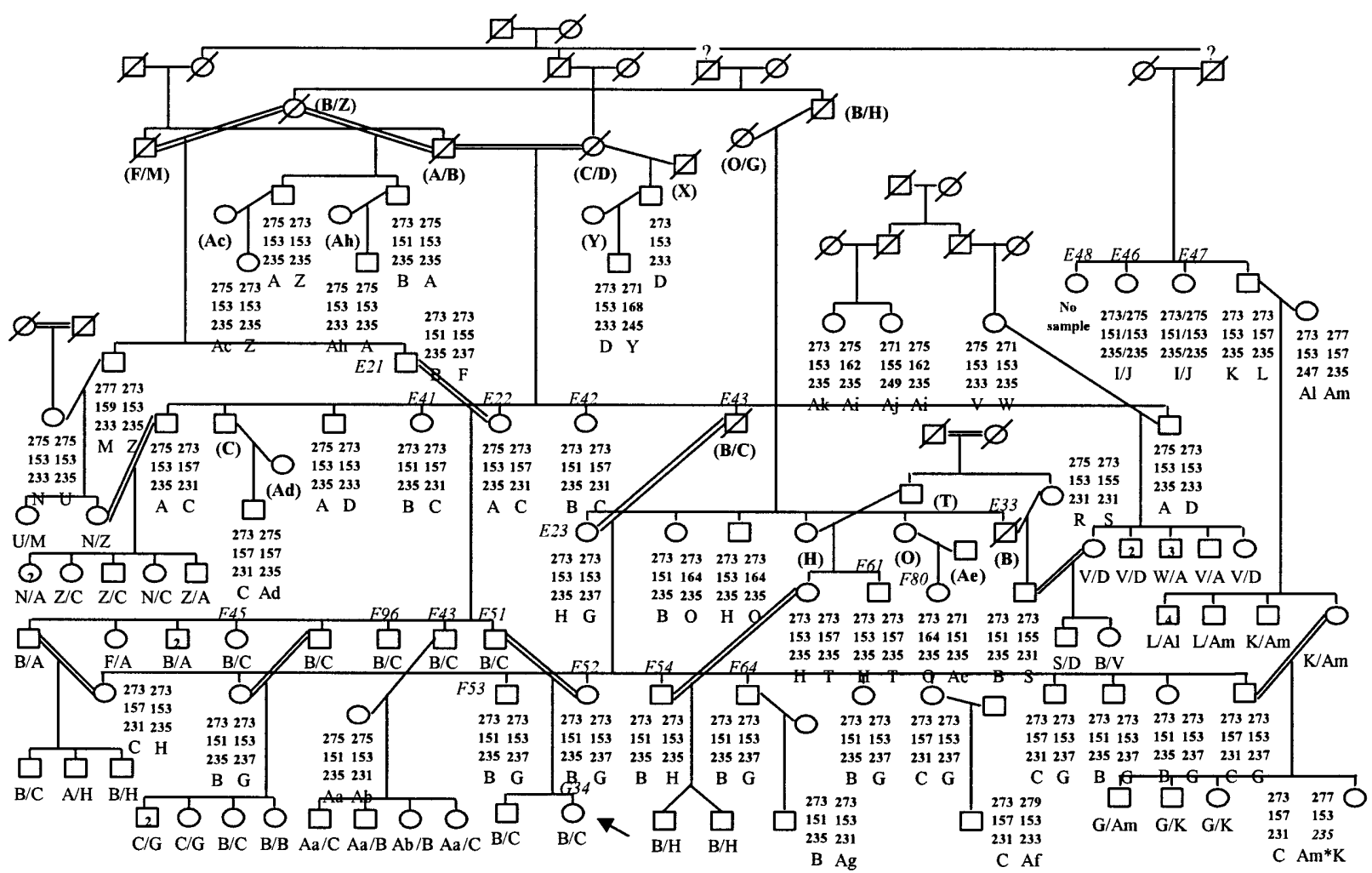

Fig. 4. Bedouin Arab family with 21 members with type $1 \mathrm{~A}$ diabetes

$(\mathrm{LOD}=2.36)]$ with two additional new loci implicated (16q22-24 and 1q52) [107]. Only the 16q22-24 locus had a LOD score (3.93) in the significant (LOD $>3.6, p<2.2 * 10^{-5}$ ) rather than the suggestive range (LOD $>2.2, p<7.4 * 10^{-4}$ ).

IDDM1 8 is located near the gene encoding the p40 subunit of interleukin-12 (IL-12 p40 gene) and IL-12 was implicated in the pathogenesis of type 1A diabetes in the NOD mouse. A significant bias in transmission has been observed for different 3' UTR alleles in affected pairs of siblings, and in an independent cohort of simplex families. The IL12B 3' UTR alleles showed different rates of expression in cell lines [117]. A number of other studies are apparently evaluating this region without finding the same association. Replication of a putative locus theoretically requires more families than the initial study to have sufficient power, but it is hoped that negative studies, if available, will be published so that the sum of information from multiple studies can be compared.

A SNP allele in the interleukine1-type 1 receptor (IL1R1) apparently leads to low plasma concentrations of IL-1-R1 and was reported to be associated with type 1A diabetes [129]. In Japanese patients, but not in Italian patients, an Arg140Trp mutation has been identified in the CD38 gene, which is a non-lineage pleiotropic cell surface receptor. Antibo- dies to CD38 have been detected in serum in $19 \%$ of patients with type $1 \mathrm{~A}$ diabetes and $16.7 \%$ with Type II diabetics [130]. Polymorphisms in the promoter region of the LRP5 gene have been associated with type 1A diabetes. LRP5 is a member of the low-density lipoprotein receptor family that is expressed in cells of the mononuclear-phagocyte system, the islets of Langerhans, vitamin A-metabolising cells, and CNS neurons [131]. Vitamin D receptor polymorphisms have been associated with risk for type 1A diabetes in several populations [132, 133, 134, 135].

\section{Developing approaches to identifying contributing genes}

The difficulty of conclusively identifying polymorphisms of specific genes influencing diabetes risk in the majority of patients with type 1A in humans and mice attests to the likely importance of novel approaches. The genome project provides important new information and a detailed scaffold for searching for relevant regions and genes. Recent papers [136, 137], concerning inflammatory bowel disease illustrates one approach. Multiple haplotypes defined by contiguous identical alleles of single nucleotide polymorphisms can be used to subdivide extended regions of the genome. Often the majority of chromosomes within a population have only one to three dominant haplotypes, and disease susceptibility can be associated with an extended region defined by one or more haplotypes. Most polymorphisms within a given haploty- 
pic region are thus associated with disease. In some instances such haplotypes will limit the ability to pinpoint any single gene contributing to disease but in other instances they can help define better the region of interest. Another approach will be the use of methods that allow the analysis of thousands of genes and their proteins (proteomics) to define pathways or specific genes contributing to disease $[138,139,140$, 141]. For instance the function of the scurfy protein and XPID gene are not yet known but investigators can apply the above techniques to define a series of genes whose messenger RNA or proteins influence disease.

\section{"Monogenic" diabetes syndromes}

There are two syndromes that include immune-mediated diabetes and that have a known major gene responsible for their aetiology. Although the aetiology of sporadic type 1A diabetes is probably oligo or polygenic, the study of these monogenic syndromes can clarify the mechanisms and pathways that lead to the loss of self-tolerance in immune-mediated diabetes.

Autoimmune polyendocrine syndrome type 1 (APS$1)$. The autoimmune polyendocrinopathy-candidiasis-ectodermal dystrophy (APECED) syndrome, also known as autoimmune polyendocrine syndrome type 1 (APS-1), has a monogenic autosomal recessive inheritance pattern. It is a rare condition, with a reported prevalence ranging between 1:80000 in Norway [142] to 1:14000 in Sardinia [143]. APS-1 is characterized by multiple autoimmune endocrinopathies, chronic mucocutaneous candidiasis and ectodermal dystrophies. [144] To diagnose this syndrome at least two of the three following disorders are required: primary hypoparathyroidism, Addison's disease and chronic mucocutaneous candidiasis. Other immune disorders also common among patients with APS-1 are type 1A diabetes, autoimmune hepatitis, vitiligo, alopecia, ovarian failure, and lymphocytic hypophysitis. APS-1 typically presents in childhood and additional autoimmune manifestations evolve throughout life. Immunosuppressive therapy has been advocated for severe cases [145]. This syndrome shows a penetrance of $100 \%$, a $1: 1$ male to female ratio and it is not associated with HLA, as opposed to most autoimmune diseases and syndromes where the penetrance is usually variable, there is higher female to male ratio and there is an HLA-association. A negative association (protection) between the DQB1*0602 allele and type $1 \mathrm{~A}$ diabetes has been recently reported in a Finnish series of patients with APS-1, suggesting that this allele is protective for type $1 \mathrm{~A}$ diabetes in both its sporadic form and within the APECED syndrome [146].
Organ-specific autoantibodies associated with each of these disorders are usually seen before the clinical onset of the disease. The positive predictive value of certain autoantibodies in relation to the specific disease, however, could be lower in patients with APS-1 than for example among relatives of patients with type $1 \mathrm{~A}$ diabetes. GAD anti-islet autoantibodies (as isolated autoantibody) in individuals with this syndrome is a common finding and does not predict a high risk of progression to diabetes [147] whereas individuals with ICA512 (IA-2) autoantibodies more frequently progress to diabetes.

The gene causing APS- 1 was isolated by positional cloning by two independent groups [148, 149] This gene is called autoimmune regulator (AIRE-1) and it maps to chromosome 21. Over 31 different mutations in the AIRE- 1 gene have been described. The most frequent mutations are a 13-bp deletion in exon 8 (1085-1097 del) among Norwegian patients [142]; a Arg257Stop mutation among Finnish; R139X in Sardinia [143]; R257X in Northern Italy; 1096-1097insCCTG, 1094-1106del, R203X and X546C [150]; 1094-1106del and R257 in an ethnically mixed population in North America [151]; a 13-bp deletion (964del13) mutation in Britain [152]; a missense mutation (Pro326Leu) in a large French family [153]. To date, no correlation has been found between specific mutations and variation in clinical phenotype. The AIRE gene encodes a 545-aminoacid protein with two putative PHD zinc fingers, a proline-rich region, and three LXXLL motifs. A nuclear localization signal, an "ASS" domain and a putative DNA-binding "SAND" domain suggest that the AIRE protein is a transcription factor [154]. Indeed, it has been shown that AIRE fused to a heterologous DNA binding domain to activate transcription. The same authors showed that the common transcriptional co-activator CREB-binding protein (CBP) interacted with AIRE in vitro and in yeast nuclei.[154] The AIRE protein is mainly localized to nuclear dot-like structures and at least in transfected cells, to cytoskeletal filaments. Mutated AIRE has an altered subcellular location in cultured cells [155]. The wild-type APS-1 protein tethered to the Gal4 DNA-binding domain acted as a strong transcriptional activator of reporter genes in mammalian cells, whereas most of the analysed mutant polypeptides had lost this capacity [156]. Human AIRE is expressed in the medullar epithelial cells and monocyte-dendritic cells of the thymus with lower expression in the spleen, foetal liver, and lymph node paracortex and medulla. The AIRE protein was not found in target organs of autoimmune destruction [157]. In adult mice, however, AIRE expression was found in bone marrow, kidney, testis, adrenal gland, liver and ovary [158, 159]. The human and mouse AIRE promoters have conserved sites for several thymus-specific transcription factors consistent with its expression in rare cells of the thy- 


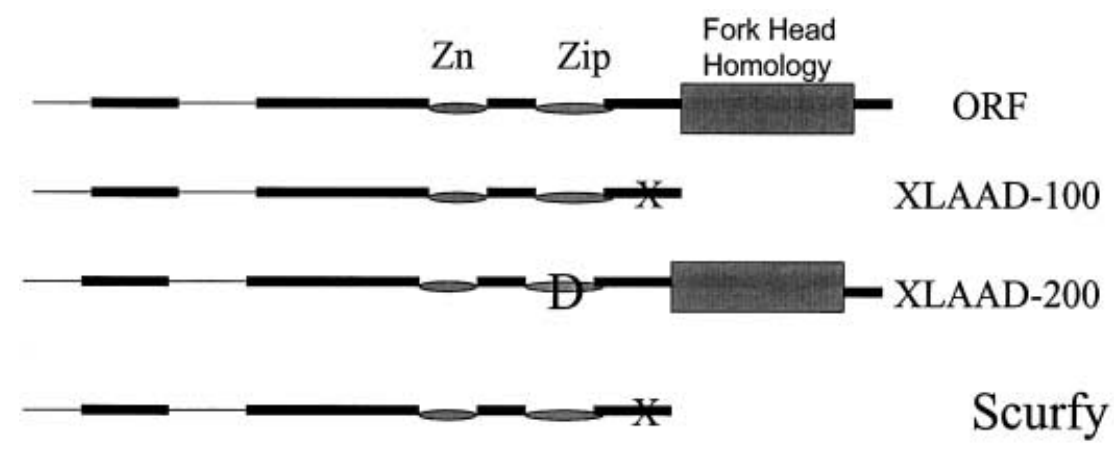

$\mathrm{Zn}=$ Zinc-finger domain, Zip = Zip Motif

$\mathrm{ORF}=$ Predicted Open Reading Frame

Fig. 5. The gene mutated in XPID (XLAAD) syndrome with the mutations of two families $(100,200)$ and the mouse mutation indicated

mus medulla, lymph nodes, and foetal liver. Immunofluorescence labelling of peripheral blood mononuclear leukocytes also showed a nuclear body-like staining pattern in a fraction of these cells [160]. The predicted human and mouse proteins are $71 \%$ identical $[161,162]$. The mouse AIRE gene, on chromosome 10 , has been cloned $[163,161]$ and has 11 alternative splice variants [159]. The mouse AIRE protein (designated 'aire') is absent in the thymus of RelB-deficient mouse and has an abnormal morphology in the thymus of the NOD mouse [164]. Of interest, during early development in mice, thymic AIRE transcription is critically dependent on RelB and occurs in epithelial cells in response to lymphocyte-mediated signals. In adult tissue AIRE expression is confined to the medulla and the cortico-medullar junction, where it is modulated by thymocytes undergoing negative selection. It has been proposed that AIRE could determine thymic stromal organisation and with it the induction of self-tolerance [165]. These observations, together with the findings of insulin production by macrophage-dendritic cells within the thymus and lymphoid organs could underlie insulin gene polymorphisms influencing diabetes risk.

Mutations in AIRE-1 have not been implicated in APS-2 or in sporadic autoimmune disease [166]. Heterozygous (one-allele) mutations in AIRE-1 have been reported in parents of patients with APS-1, patients with sporadic Addison's disease, autoimmune thyroiditis or ovarian failure, and also in control subjects [167, 166, 168]. Heterozygous mutations in AIRE-1 are not more frequent in patients with isolated autoimmune disease compared to healthy control subjects and therefore AIRE-1 does not seem to be a susceptibility locus for sporadic autoimmune disease $[169,170,171]$.
$X P I D / X L A A D$. A syndrome affecting males only with diabetes mellitus, thyroiditis, diarrhoea, haemolytic anaemia, eczematoid rashes, immunodeficiency and death during infancy was first described in 1982 [172]. This syndrome is known by various names, including X-linked autoimmunity-allergic disregulation syndrome (XLAAD), X-linked polyendocrinopathy, immune dysfunction, and diarrhoea (XPID) or Xlinked autoimmunity-immunodeficiency syndrome (XLAID). It is an X-linked recessive immunological disorder characterized by early-onset type $1 \mathrm{~A}$ diabetes and severe atopy, including eczema, food allergy, and eosinophilic inflammation. Patients can also have autoimmune thyroiditis, haemolytic anaemia, chronic autoimmune diarrhoea, failure to thrive, recurrent infections, increased $\operatorname{IgE}$ concentrations and eosinophilia. The cause of the associated immunodeficiency is not clear and leukocyte count, lymphocyte subsets and T-cell proliferation tests are usually normal. T lymphocytes in these patients have a cytokine profile markedly skewed toward a Th2 phenotype (high concentration of IL-4, IL-5 and IL-13, low concentration of IFN-gamma) [173, 174]. Several mutations in JM2, a gene in the pericentromeric region of the X chromosome (Xp11.23-Xq13.3) have been described in patients with XPID [175, 173, 176] (Fig.5). This interval also harbours the gene for Wiskott Aldrich syndrome but mutations in the Wiskott Aldrich protein (WASP) gene have not been found in patients with XPID $[175,177]$. The predicted wild-type protein, named scurfin or Foxp3, contains a winged helix [fork head homology domain (FKH)] motif at the carboxy terminus, a $\mathrm{C} 2 \mathrm{H} 2$ zinc finger domain $(\mathrm{Zn})$ and a 3-heptad Zip motif upstream of the FKH, suggesting that this protein functions as a transcription factor. Mutation of the same gene in mice produces "Scurfy". Scurfy is associated with hypergammaglobulinaemia, low platelet and erythrocyte counts, and mice die from wasting syndrome secondary to overproduction of cytokines. Scurfy resembles WiskottAldrich syndrome in humans [178]. Both central (thymic) and peripheral tolerance are defective in Scurfy 
mice [179]. Bone marrow transplantation cures mice with the Scurfy mutation and given the severity of the disease it has been tried in humans [180]. A single child with the disease developed mixed chimerism and the disease remitted for 2 years after bone marrow transplantation but unfortunately the patient eventually succumbed to a poorly characterized haematological disorder.

\section{Conclusion}

Anti-islet autoantibodies, insulitis, and immunemediated diabetes occur spontaneously or can be induced in multiple strains of rats and mice, and occur in humans with monogenic disorders of immune function or individuals with specific but relatively common HLA genotypes. Thus both the genetic factors and environmental determinants leading to type $1 \mathrm{~A}$ diabetes are relatively common. Studies of children followed from birth (e.g. DAISY and BabyDiab) indicate that relatives of patients can be identified with HLA typing with a risk exceeding $25 \%$ of progressing to anti-islet autoimmunity and then diabetes. The current ability to define high genetic risk should aid in the search for contributing environmental factors. It is clear that type $1 \mathrm{~A}$ diabetes is heterogeneous and this heterogeneity will complicate efforts to improve genetic prediction given the dominant influence of HLA alleles. Nevertheless there are likely to be common immunologic pathways underlying disease risk, the discovery of which will facilitate development of rationale therapies for the prevention of this increasingly common disorder.

Sources. The review is based on the relevant literature published in the English language during the period 1980-2001, and seminal prior contributions. The sources available to the authors were integrated with sources identified through PubMed searches for "type 1 diabetes and genetics", "type 1 diabetes and HLA", "type 1 diabetes and insulin gene", "type 1 diabetes and CTLA", "IDDM", "type 1 diabetes and twin study", "XPID”, "APECED”, "XLAD”.

Acknowledgements. This is supported by: NIH Autoimmunity Center of Excellence U19 AI46374, Juvenile Diabetes Foundation Fellowship (MR), Diabetes Endocrine Research Center P30 DK57516, NIH grants DK 32083, DK32493, DK46639, DK55969, AI44431, DK57538, Juvenile Diabetes Foundation (JDF\#1-2000-226), American Diabetes Association (ADA PN9701-132), and Clinical Research Center grants at University Hospital RR00051, and at Children's Hospital RR0009). We thank Pam Fain for review and discussion of the manuscript.

\section{References}

1. Risch N, Ghosh S, Todd JA (1993) Statistical evaluation of multiple-locus linkage data in experimental species and its relevance to human studies: application to nonobese diabetic (NOD) mouse and human insulin- dependent diabetes mellitus (IDDM). Am J Hum Genet 53: 702-714

2. Todd JA, Farrall M (1996) Panning for gold: genome-wide scanning for linkage in type I diabetes. Hum Mol Genet 5: 1443-1448

3. Warram JH, Krolewski AS, Gottlieb MS, Kahn CR (1984) Differences in risk of insulin-dependent diabetes in offspring of diabetic mothers and diabetic fathers. N Engl J Med 311: 149-152

4. Tillil H, Kobberling J (1987) Age-correlated empirical genetic risk estimates for first-degree relatives of IDDM patients. Diabetes 36: 93-99

5. Bleich D, Polak M, Eisenbarth GS, Jackson RA (1993) Decreased risk of type I diabetes in offspring of mothers who acquire diabetes during adrenarchy. Diabetes 42: 1433-1439

6. Cucca F, Goy JV, Kawaguchi Y et al. (1998) A male-female bias in type 1 diabetes and linkage to chromosome $\mathrm{Xp}$ in MHC HLA-DR3-positive patients. Nat Genet 19: 301-302

7. Weets I, Van Autreve J, van der Auwera BJ et al. (2001) Male-to-female excess in diabetes diagnosed in early adulthood is not specific for the immune-mediated form nor is it HLA-DQ restricted: possible relation to increased body mass index. Diabetologia 44: 40-47

8. Martin N, Boomsma D, Machin G (1997) A twin-pronged attack on complex traits. Nat Genet 17: 387-392

9. Phillips DIW (1993) Twin studies in medical research: can they tell us whether disease are genetically determined?. Lancet 341: 1008-1009

10. Smith C (1974) Concordance in twins: methods and interpretation. Am J Hum Genet 26: 454-466

11. Hawa M, Rowe R, Lan MS et al. (1997) Value of antibodies to islet protein tyrosine phosphatase-like molecule in predicting type 1 diabetes. Diabetes 46: 1270-1275

12. Kumar D, Gemayel NS, Deapen D et al. (1993) NorthAmerican twins with IDDM. Genetic, etiological, and clinical significance of disease concordance according to age, zygosity, and the interval after diagnosis in first twin. Diabetes 42: 1351-1363

13. Lorenzen T, Pociot F, Hougaard P, Nerup J (1994) Longterm risk of IDDM in first-degree relatives of patients with IDDM. Diabetologia 37: 321-327

14. Redondo MJ, Rewers M, Yu L et al. (1999) Genetic determination of islet cell autoimmunity in monozygotic twin, dizygotic twin, and non-twin siblings of patients with type 1 diabetes: prospective twin study. BMJ 318: 698-702

15. Verge CF, Gianani R, Yu L et al. (1995) Late progression to diabetes and evidence for chronic $\beta$-cell autoimmunity in identical twins of patients with type I diabetes. Diabetes 44: $1176-1179$

16. Srikanta S, Ganda OP, Eisenbarth GS, Soeldner JS (1983) Islet cell antibodies and beta cell function in monozygotic triplets and twins initially discordant for Type I diabetes mellitus. N Engl J Med 308: 322-325

17. Petersen JS, Kyvik KO, Bingley PJ et al. (1997) Population based study of prevalence of islet cell autoantibodies in monozygotic and dizygotic Danish twin pairs with insulin dependent diabetes mellitus. BMJ 314: 1575-1579

18. Kaprio J, Tuomilehto J, Koskenvuo M et al. (1992) Concordance for Type I (insulin-dependent) and Type II 
(non-insulin-dependent) diabetes mellitus in a population-based cohort of twins in Finland. Diabetologia 35: 1060-1067

19. Johnston C, Pyke DA, Cudworth AG, Wolf E (1983) HLA-DR typing in identical twins with insulin-dependent diabetes: difference between concordant and discordant pairs. BMJ 286: 253-255

20. Redondo MJ, Yu L, Hawa M et al. (2001) Heterogenity of Type I diabetes: analysis of monozygotic twins in Great Britain and the United States. Diabetologia 44: 354-362

21. Olmos P, A'Hearn R, Heaton DA et al. (1988) The significance of the concordance rate of Type I (insulin-dependent) diabetes mellitus in identical twins. Diabetologia 31: 747-750

22. Kawano K, Hirashima T, Moris S, Saitoh Y, Kurosumi M, Natori T (1991) New inbred strain of Long-Evans Tokushima lean rats with IDDM without lymphopenia. Diabetes 40: 1375-1381

23. Mordes JP, Bortell R, Doukas J et al. (1996) The BB/Wor rat and the balance hypothesis of autoimmunity. Diabetes Metab Rev 12: 103-109

24. Markholst H, Eastman S, Wilson D, Andreasen BE, Lernmark $\AA$ (1991) Diabetes segregates as a single locus in crosses between inbred $\mathrm{BB}$ rats prone or resistant to diabetes. J Exp Med 174: 297-300

25. Ellerman KE, Like AA (2000) Susceptibility to diabetes is widely distributed in normal class IIu haplotype rats. Diabetologia 43: 890-898

26. Ellerman KE, Richards CA, Guberski DL, Shek WR, Like AA (1996) Kilham rat virus triggers T-cell-dependent autoimmune diabetes in multiple strains of rat. Diabetes 45 : 557-562

27. Abiru N, Maniatis AK, Yu L et al. (2001) Peptide and MHC Specific Breaking of Humoral Tolerance to Native Insulin with the B:9-23 Peptide in Diabetes Prone and Normal Mice. Diabetes 50: 1274-1281

28. Nerup J, Platz P, Anderson OO et al. (1974) HLA antigens and diabetes mellitus. Lancet ii: $864-866$

29. Eisenbarth GS, Wilson P, Ward F, Lebovitz HE (1978) HLA type and occurrence of disease in familial polyglandular failure. N Engl J Med 298: 92-94

30. Park YS, Wang CY, Ko KW et al. (1998) Combinations of HLA DR and DQ molecules determine the susceptibility to insulin-dependent diabetes mellitus in Koreans. Hum Immunol 59: 794-801

31. Wen L, Chen NY, Tang J, Sherwin R, Wong FS (2001) The regulatory role of DR4 in a spontaneous diabetes DQ8 transgenic model. J Clin Invest 107: 871-880

32. Ziegler R, Alper CA, Awdeh ZL et al. (1991) Specific association of HLA-DR4 with increased prevalence and level of insulin autoantibodies in first-degree relatives of patients with type I diabetes. Diabetes 40: 709-714

33. Pugliese A, Gianani R, Moromisato R et al. (1995) HLADQB1*0602 is associated with dominant protection from diabetes even among islet cell antibody-positive first-degree relatives of patients with IDDM. Diabetes 44: 608-613

34. Kwon OJ, Brautbar C, Weintrob N et al. (2001) Immunogenetics of HLA class II in Israeli Ashkenazi Jewish, Israeli non-Ashkenazi Jewish, and in Israeli Arab IDDM patients. Hum Immunol 62: 85-91

35. Pugliese A, Bugawan T, Moromisato R et al. (1994) Two subsets of HLA-DQA1 alleles mark phenotypic variation in levels of insulin autoantibodies in first degree relatives at risk for insulin-dependent diabetes. J Clin Invest 93: $2447-2452$
36. Baisch JM, Weeks T, Giles R, Hoover M, Stastny P, Capra JD (1990) Analysis of HLA-DQ genotypes and susceptibility in insulin- dependent diabetes mellitus. N Engl J Med 322: 1836-1841

37. Gianani R, Verge CF, Moromisato-Gianani RI et al. (1996) Limited loss of tolerance to islet autoantigens in ICA + first degree relatives of patients with type I diabetes expressing the HLA DQB1*0602 allele. J Autoimmun 9: 423-425

38. Gianani R, Pugliese A, Bonner-Weir S et al. (1992) Prognostically significant heterogeneity of cytoplasmic islet cell antibodies in relatives of patients with type I diabetes. Diabetes 41: 347-353

39. Verge, CF, Gianani R, Kawasaki E et al. (1996) Prediction of type I diabetes in first-degree relatives using a combination of insulin, GAD, and ICA512bdc/IA-2 autoantibodies. Diabetes 45: 926-933

40. Greenbaum CJ, Cuthbertson D, Eisenbarth GS, Schatz DA, Zeidler A, Krischer JP (2000) Islet cell antibody positive relatives with HLA-DQA1*0102, DQB1*0602: Identification by the Diabetes Prevention Trial-1. J Clin Endocrinol Metab 85: 1255-1260

41. Solimena M, Folli F, Aparisi R, Pozza G, De Camilli P (1990) Autoantibodies to GABA-ergic neurons and pancreatic beta cells in stiff-man syndrome. N Engl J Med 322: $1555-1560$

42. Hoover ML, Marta RT (1997) Molecular Modelling of HLA-DQ suggests a mechanism of resistance in type I diabetes. Scand J Immunol 45: 193-202

43. Pugliese A, Kawasaki E, Zeller M et al. (1999) Sequence analysis of the diabetes-protective human leukocyte antigen-DQB1*0602 allele in unaffected, islet cell antibodypositive first degree relatives and in rare patients with type 1 diabetes. J Clin Endocrinol Metab 84: 1722-1728

44. Erlich HA, Griffith RL, Bugawan TL, Ziegler R, Alper C, Eisenbarth GS (1991) Implication of specific DQB1 alleles in genetic susceptibility and resistance by identification of IDDM siblings with novel HLA-DQB1 allele and unusual DR2 and DR1 haplotypes. Diabetes 40: 478-481

45. Redondo MJ, Kawasaki E, Mulgrew CL et al. (2000) DR and DQ associated protection from type 1 diabetes: comparison of DRB1*1401 and DQA1*0102-DQB1*0602. J Clin Endocrinol Metab 85: 3793-3797

46. She JX, Ellis TM, Wilson SB et al. (1999) Heterophile antibodies segregate in families and are associated with protection from type 1 diabetes. Proc Natl Acad Sci U S A 96: 8116-8119

47. Redondo MJ, Gottlieb PA, Motheral T et al. (1999) Heterophile anti-mouse immunoglobulin antibodies may interfere with cytokine measurements in patients with HLA alleles protective for type 1A diabetes. Diabetes 48: 2166-2170

48. Spielman RS, Ewens WJ (1996) The TDT and other family-based tests for linkage disequilibrium and association. Am J Hum Genet 59: 983-989

49. Kawasaki E, Noble J, Erlich H, Mulgrew CL, Fain PR, Eisenbarth GS (1998) Transmission of DQ haplotypes to patients with type 1 diabetes. Diabetes 47: 1971-1973

50. Human Leukocyte Antigen (HLA) (1988) American Society of Histocompatibility and Immunogenetics, Lenexa, Kansas

51. Ronningen KS, Spurkland A, Iwe T, Vartdal F, Thorsby E (1991) Distribution of HLA-DRB1,-DQA1 and -DQB1 alleles and DQA1-DQB1 genotypes among Norwegian patients with insulin-dependent diabetes mellitus. Tissue Antigens 37: 105-111 
52. Pugliese A, Awdeh Z, Galluzzo A, Yunis EJ, Alper CA, Eisenbarth GS (1992) No independent association between HSP70 gene polymorphism and IDDM. Diabetes 41: 788-791

53. Garcia-Merino A, Alper CA, Usuku K et al. (1996) Tumor necrosis factor (TNF) microsatellite haplotypes in relation to extended haplotype, susceptibility to diseases associated with the major histocompatibility complex and TNF secretion. Hum Immunol 50: 11-21

54. Ettinger RA, Liu AW, Nepom GT, Kwok WW (1998) Exceptional stability of the HLA-DQA1*0102/DQB1*0602 alpha beta protein dimer, the class II MHC molecule associated with protection from insulin-dependent diabetes mellitus. J Immunol 161: 6439-6445

55. Ridgway WM, Fasso M, Fathman CG (1999) A new look at MHC and autoimmune disease. Science 284: 749-751

56. Latek RR, Suri A, Petzold SJ et al. (2000) Structural basis of peptide binding and presentation by the type I diabetes-associated MHC class II molecule of NOD mice. Immunity 12: 699-710

57. Lee KH, Wucherpfennig KW, Wiley DC (2001) Structure of a human insulin peptide/HLA-DQ8 complex and susceptibility to type 1 diabetes. Nat Immunol 2: 501-507

58. Aparicio JMR, Wakisaka A, Takada A, Matsuura N, Aizawa M (1988) HLA-DQ system and insulin-dependent diabetes mellitus in Japanese: does it contribute to the development of IDDM as it does in Caucasians?. Immunogenetics 28: 240-246

59. Morel PA, Dorman JS, Todd JA, McDevitt HO, Trucco M (1988) Aspartic acid at position 57 of the HLA-DQ beta chain protects against type I diabetes: a family study. Proc Natl Acad Sci USA 85: 8111-8115

60. Wen L, Wong FS, Tang J et al. (2000) In vivo evidence for the contribution of human histocompatibility leukocyte antigen (HLA)-DQ molecules to the development of diabetes. J Exp Med 191: 97-104

61. Corper AL, Stratmann T, Apostolopoulos V et al. (2000) A structural framework for deciphering the link between I-Ag7 and autoimmune diabetes. Science 288: 505-511

62. Anderson B, Park BJ, Verdaguer J, Amrani A, Santamaria $\mathrm{P}$ (1999) Prevalent $\mathrm{CD}^{+} \mathrm{T}$ cell response against one peptide/MHC complex in autoimmune diabetes. Proc Natl Acad Sci USA. 96: 9311-9316

63. Schmidt D, Amrani A, Verdaguer J, Bou S, Santamaria P (1999) Autoantigen-independent deletion of diabetogenic CD 4 + thymocytes by protective MHC class II molecules. J Immunol 162: 4627-4636

64. Wucherpfennig KW, Eisenbarth GS (2001) Type 1 Diabetes. Nat Immunol 2: 1-3

65. Park Y, Eisenbarth GS (2001) Genetic susceptibility factors of type 1 diabetes in Asians. Diabetes Metab Res Rev 17: 2-11

66. Zavattari P, Lampis R, Motzo C et al. (2001) Conditional linkage disequilibrium analysis of a complex disease superlocus, IDDM1 in the HLA region, reveals the presence of independent modifying gene effects influencing the type 1 diabetes risk encoded by the major HLA-DQB1, -DRB1 disease loci. Hum Mol Genet 10: 881-889

67. Park YS, Eisenbarth GS, Lee H, Sanjeevi CB (2001) MICA Polymorphism is Associated with Type 1 Diabetes in the Korean Population. Diabetes Care 24: 33-38

68. Awdeh ZL, Raum D, Yunis EJ, Alper CA (1983) Extended HLA/complement allele haplotypes: evidence for T/t-like complex in man. Proc Natl Acad Sci USA 80: 259-263

69. Raum D, Awdeh Z, Yunis EJ, Alper CA, Gabbay KH (1984) Extended major histocompatibility complex haplotypes in type I diabetes mellitus. J Clin Invest 74: 449-454
70. Dawkins RL, Martin E, Saueracker G, Kay PH, Leaver A, Christiansen FT (1990) Supratypes and ancestral haplotypes in IDDM: potential importance of central nonHLA MHC genes. J Autoimmun 3: 63-68

71. Redondo MJ, Eisenbarth GS (1997) Autoimmune Polyendocrine Syndrome Type II. In: Eisenbarth GS (ed) Endocrine and Organ Specific Autoimmunity, RG Landes Company, Austin, pp 41-61

72. Eisenbarth GS, Wilson PW, Ward F, Buckley C, Lebovitz HE (1979) The polyglandular failure syndrome: disease inheritance, HLA- type and immune function. Ann Intern Med 91: 528-533

73. Neufeld M, Maclaren NK, Blizzard RM (1981) Two types of autoimmune Addison's disease associated with different polyglandular autoimmune (PGA) syndromes. Medicine (Baltimore) 60: 355-362

74. Partanen J, Peterson P, Westman P, Aranko S, Krohn K (1994) Major histocompatibility complex class I and II in Addison's disease. MHC alleles do not predict autoantibody specificity and 21-hydroxylase gene polymorphism has no independent role in disease specificity. Hum Immunol 41: 135-140

75. Raum D, Awdeh Z, Yunis E J, Alper CA, Gabbay KH (1996) Extended major histocompatibility complex haplotypes in type I diabetes mellitus. J Clin Invest 74: 449-454

76. Nepom GT, Erlich H (1991) MHC class-II molecules and autoimmunity. Ann Rev Immunol 9: 493-525

77. Soderbergh A, Winqvist O, Norheim I et al. (1996) Adrenal autoantibodies and organ-specific autoimmunity in patients with Addison's disease. Clin Endocrinol (Oxf) 45: 453-460

78. Falorni A, Laureti S, Nikoshkov A et al. (1997) 21-hydroxylase autoantibodies in adult patients with endocrine autoimmune diseases are highly specific for Addison's disease. Clin Exp Immunol 107: 341-346

79. Tanaka H, Perez MS, Powell M et al. (1997) Steroid 21hydroxylase autoantibodies: measurements with a new immunoprecipitation assay. J Clin Endocrinol Metab 82: 1440-1446

80. Yu L, Brewer KW, Gates S et al. (1999) DRB1*04 and DQ alleles: expression of 21-hydroxylase autoantibodies and risk of progression to Addison's disease. J Clin Endocrinol Metab 84: 328-335

81. Brewer KW, Parziale VS, Eisenbarth GS (1997) Screening patients with insulin-dependent diabetes mellitus for adrenal insufficiency. N Engl J Med 337: 202

82. Bao F, Yu L, Babu S et al. (1999) One third of HLA DQ2 homozygous patients with type 1 diabetes express celiac disease associated transglutaminase autoantibodies. J Autoimmun 13: 143-148

83. Hoffenberg EJ, Bao F, Eisenbarth GS et al. (2000) Transglutaminase antibodies in children with a genetic risk for celiac disease. J Pediatr 137: 356-360

84. Pugliese A, Solimena M, Awdeh ZL et al. (1993) Association of HLA-DQB1*0201 with stiff-man syndrome. J Clin Endocrinol Metab 77: 1550-1553

85. Bennett ST, Lucassen AM, Gough SCL et al. (1995) Susceptibility to human type I diabetes at IDDM2 is determined by tandem repeat variation at the insulin gene minisatellite locus. Nat Genet 9: 284-292

86. Bell GI, Horita S, Karam JH (1984) A polymorphic locus near the human insulin gene is associated with insulin-dependent diabetes mellitus. Diabetes 33: 176-183

87. Bennett ST, Wilson AJ, Cucca F et al. (1996) IDDM2VNTR-encoded susceptibility to type 1 diabetes: dominant protection and parental transmission of alleles of the insulin gene-linked minisatellite locus. J Autoimmun 9: 415-421 
88. Jolicoeur C, Hanahan D, Smith KM (1994) T-cell tolerance toward a transgenic $\beta$-cell antigen and transcription of endogenous pancreatic genes in thymus. Proc Natl Acad Sci USA 91: 6707-6711

89. Smith KM, Olson DC, Hirose R, Hanahan D (1997) Pancreatic gene expression in rare cells of thymic medulla: evidence for functional contribution to $\mathrm{T}$ cell tolerance. Int Immunol 9: 1355-1365

90. Moore GE, Abu-Amero SN, Bell G et al. (2001) Evidence that insulin is imprinted in the human yolk sac. Diabetes 50: 199-203

91. Pugliese A, Zeller M, Fernandez A et al. (1997) The insulin gene is transcribed in the human thymus and transcription levels correlate with allelic variation at the INS VNTR-IDDM2 susceptibility locus for type I diabetes. Nat Genet 15: 293-297

92. Diez J, Zeller M, Park Y et al. (2001) Differential splicing of the IA-2 nRNA in pancreas and lymphoid organs as a permissive genetic mechanism for autoimmunity against the IA-2 type 1 diabetes autoantigen. Diabetes 50: 895-900

93. Pugliese A, Brown D, Garza D et al. (2001) Self-Antigen Presenting Cells Expressing Islet Cell Molecules in $\mathrm{Hu}-$ man Thymus and Peripheral Lymphoid Organs: Phenotypic Characterization and Implications for Immunological Tolerance and Type 1 Diabetes. J Clin Invest 107: 555-564

94. Pugliese A, Awdeh ZL, Alper CA, Jackson RA, Eisenbarth GS (1994) The paternally inherited insulin gene B allele $(1,428$ FokI site) confers protection from insulin-dependent diabetes in families. J Autoimmun 7: 687-694

95. Sospedra M, Ferrer-Francesch X, Dominguez O, Juan M, Foz-Sala M, Pujol-Borrell R (1998) Transcription of a broad range of self-antigens in human thymus suggests a role for central mechanisms in tolerance toward peripheral antigens. J Immunol 161: 5918-5929

96. Field LL, Tobias R, Thomson G, Plon S (1996) Susceptibility to insulin-dependent diabetes mellitus maps to a locus (IDDM11) on human chromosome 14q24.3-q31. Genomics 33: 1-8

97. Fu J, Ikegami H, Kawaguchi Yet al. (1998) Association of distal chromosome $2 \mathrm{q}$ with IDDM in Japanese subjects. Diabetologia 41: 228-232

98. Paterson AD, Petronis A (2000) Age and sex based genetic locus heterogeneity in type 1 diabetes. J Med Genet 37: 186-191

99. Paterson AD, Petronis A (1999) Sex of affected sibpairs and genetic linkage to type 1 diabetes. Am J Med Genet 84: $15-19$

100. Field LL, Tobias R, Magnus T (1996) A locus on chromosome 15q26(IDDM3) produces susceptibility to insulindependent diabetes mellitus. Nat Genet 8: 189-194

101. Bui MM, Luo DF, She JYet al. (1996) Paternally transmitted IDDM2 influences diabetes susceptibility despite biallelic expression of the insulin gene in human pancreas. $\mathrm{J}$ Autoimmun 9: 97-103

102. Davies JL, Kawaguchi S, Bennett ST, Copeman JB, Cordell HJ, Pritchard P (1994) A genome-wide search for human type 1 diabetes susceptibility genes. Nature 371: 130-136

103. Hashimoto L, Habita C, Beressi JP et al. (1994) Genetic mapping of a susceptibility locus for insulin-dependent diabetes mellitus on chromosome 11q. Nature 371: 161-164

104. Hodge SE, Anderson CE, Neiswanger K et al. (1981) Close genetic linkage between diabetes mellitus and kidd blood group. Lancet ii: 893-895

105. Merriman T, Twells R, Merriman M et al. (1997) Evidence by allelic association-dependent methods for a type 1 dia- betes polygene (IDDM6) on chromosome 18q21. Hum Mol Genet 6: 1003-1010

106. Copeman JB, Cucca F, Hearne CM et al. (1995) Linkage disequilibrium mapping of a type 1 diabetes susceptibility gene (IDDM7) to chromosome 2q31-q33. Nat Genet 9: $80-85$

107. Cox NJ, Wapelhorst B, Morrison VA et al. (2001) Seven regions of the genome show evidence of linkage to type 1 diabetes in a consensus analysis of 767 multiplex families. Am J Hum Genet 69: 820-830

108. Luo DF, Bui MM, Muir A, Maclaren NK, Thomson G, She JX (1995) Affected-sib-pair mapping of a novel susceptibility gene to insulin-dependent diabetes mellitus (IDDM8) on chromosome 6q25-q27. Am J Hum Genet 57: 911-919

109. Cornelis F, Faure S, Martinez M et al. (1998) New susceptibility locus for rheumatoid arthritis suggested by a genome-wide linkage study. Proc Natl Acad Sci USA 95: 10746-10750

110. Reed P, Cucca F, Jenkins S et al. (1997) Evidence for a type 1 diabetes susceptibility locus (IDDM10) on human chromosome 10p11-q11. Hum Mol Genet 6: 1011-1016

111. Donner H, Rau H, Walfish PG et al. (1997) CTLA4 alanine-17 confers genetic susceptibility to Graves' disease and to type-1 diabetes mellitus. J Clin Endocrinol Metab 82: $143-146$

112. Marron MP, Raffel LJ, Garchon HJ et al. (1997) Insulindependent diabetes mellitus (IDDM) is associated with CTLA4 polymorphisms in multiple ethnic groups. Hum Mol Genet 6: 1275-1282

113. Fox CJ, Paterson AD, Mortin-Toth SM, Danska JS (2000) Two genetic loci regulate T cell-dependent islet inflammation and drive autoimmune diabetes pathogenesis. Am J Hum Genet 67: 67-81

114. Morahan G, Huang D, Tait BD, Colman PG, Harrison LC (1996) Markers on distal chromosome $2 \mathrm{q}$ linked to insulin-dependent diabetes mellitus. Science 272: 1811-1813

115. Delepine M, Pociot F, Habita C et al. (1997) Evidence of a non-MHC susceptiblity locus in type I diabetes linked to HLA on chromosome 6. Am J Hum Genet 60: 174-187

116. Verge CF, Vardi P, Babu S et al. (1998) Evidence for oligogenic inheritance of type $1 \mathrm{~A}$ diabetes in a large Bedouin Arab family. J Clin Invest 102: 1569-1575

117. Morahan G, Huang D, Ymer S-I et al. (2001) Linkage disequilibrium of a type 1 diabetes susceptibility locus with a regulatory IL12B allele. Nat Genet 27: 218-221

118. Donner H, Braun J, Seidl C et al. (1997) Codon 17 polymorphism of the cytotoxic $\mathrm{T}$ lymphocyte antigen 4 gene in Hashimoto's thyroiditis and Addison's disease. J Clin Endocrinol Metab 82: 4130-4132

119. Djilali-Saiah I, Schmitz J, Harfouch-Hammoud E et al. (1998) CTLA-4 gene polymorphism is associated with predisposition to coeliac disease. Gut 43: 187-189

120. Van der Auwera BJ, Vandewalle CL, Schuit FC et al. (1997) CTLA-4 gene polymorphism confers susceptibility to insulin-dependent diabetes mellitus (IDDM) independently from age and from other genetic or immune disease markers. The Belgian Diabetes Registry. Clin Exp Immunol 110: 98-103

121. Agarwal K, Jones DE, Daly AK et al. (2000) CTLA-4 gene polymorphism confers susceptibility to primary biliary cirrhosis. J Hepatol 32: 538-541

122. Rau H, Braun J, Donner H et al. (2001) The codon 17 polymorphism of the CTLA4 gene in type 2 diabetes mellitus. J Clin Endocrinol Metab 86: 653-655

123. Marron MP, Zeidler A, Raffel LJ et al. (2000) Genetic and physical mapping of a type 1 diabetes susceptibility gene 
(IDDM12) to a $100-\mathrm{kb}$ phagemid artificial chromosome clone containing D2S72-CTLA4-D2S105 on chromosome 2q33. Diabetes 49: 492-499

124. Larsen ZM, Kristiansen OP, Mato E et al. (1999) IDDM12 (CTLA4) on 2q33 and IDDM13 on 2q34 in genetic susceptibility to type 1 diabetes (insulin-dependent). Autoimmunity 31: 35-42

125. Lowe RM, Graham J, Sund G et al. (2000) The length of the CTLA-4 microsatellite (AT)N-repeat affects the risk for type 1 diabetes. Diabetes Incidence in Sweden Study Group. Autoimmunity 32: 173-180

126. Chistiakov DA, Savost'anov KV, Nosikov VV (2001) CTLA4 gene polymorphisms are associated with, and linked to, insulin-dependent diabetes mellitus in a Russian population. BMC Med Genet 2: 6

127. Hayashi H, Kusaka I, Nagasaka S et al. (1999) Association of CTLA-4 polymorphism with positive anti-GAD antibody in Japanese subjects with type 1 diabetes mellitus. Clin Endocrinol (Oxf) 51: 793-799

128. Bao F, Babu S, Bobenhausen I et al. (2001) Single Nucleotide Polymorphism Studies of IDDM17 in Bedouin Arab and American Families from the Human Biological Data Interchange (HBDI). Diabetes 50 [Suppl 2]: A28 (Abstract)

129. Bergholdt R, Larsen ZM, Andersen NA et al. (2000) Characterization of new polymorphisms in the 5' UTR of the human interleukin-1 receptor type 1 (IL1R1) gene: linkage to type 1 diabetes and correlation to IL-1RI plasma level. Genes Immun 1: 495-500

130. Mallone R, Ortolan E, Baj G et al. (2001) Autoantibody response to CD38 in Caucasian patients with type 1 and type 2 diabetes: immunological and genetic characterization. Diabetes 50: 752-762

131. Figueroa DJ, Hess JF, Ky B et al. (2000) Expression of the type I diabetes-associated gene LRP5 in macrophages, vitamin A system cells, and the Islets of Langerhans suggests multiple potential roles in diabetes. J Histochem Cytochem 48: 1357-1368

132. Pani MA, Knapp M, Donner H et al. (2000) Vitamin D receptor allele combinations influence genetic susceptibility to type 1 diabetes in Germans. Diabetes 49: 504-507

133. Ban Y, Taniyama M, Yanagawa T et al. (2001) Vitamin D receptor initiation codon polymorphism influences genetic susceptibility to type 1 diabetes mellitus in the Japanese population. BMC Med Genet 2: 7

134. Chang TJ, Lei HH, Yeh JI et al. (2000) Vitamin D receptor gene polymorphisms influence susceptibility to type 1 diabetes mellitus in the Taiwanese population. Clin Endocrinol (Oxf) 52: 575-580

135. McDermott ME, Ramachandran A, Ogunkolade BW et al. (1997) Allelic variation in the vitamin D receptor influences susceptibility to IDDM in Indian Asians. Diabetologia 40: 971-975

136. Rioux JD, Daly MJ, Silverberg MS et al. (2001) Genetic variation in the 5q31 cytokine gene cluster confers susceptibility to Crohn disease. Nat Genet 29: 223-228

137. Daly MJ, Rioux JD, Schaffner SF et al. (2001) High-resolution haplotype structure in the human genome. Nat Genet 29: 229-232

138. Schena M, Shalon D, Heller R, Chai A, Brown PO, Davis RW (1996) Parallel human genome analysis: microarraybased expression monitoring of 1000 genes. Proc Natl Acad Sci USA 93: 10614-10619

139. Ermolaeva O, Rastogi M, Pruitt KD et al. (1998) Data management and analysis for gene expression arrays. Nat Genet 20: 19-23
140. Pollack JR, Perou CM, Alizadeh AA et al. (1999) Genome-wide analysis of DNA copy-number changes using cDNA microarrays. Nat Genet 23: 41-46

141. Wilson SB, Kent SC, Horton HF et al. (2000) Multiple differences in gene expression in regulatory Valpha 24Jalpha Q T cells from identical twins discordant for type I diabetes. Proc Natl Acad Sci USA 97: 7411-7416

142. Myhre AG, Halonen M, Eskelin P et al. (2001) Autoimmune polyendocrine syndrome type 1 (APS I) in Norway. Clin Endocrinol (Oxf) 54: 211-217

143. Rosatelli MC, Meloni A, Meloni A et al. (1998) A common mutation in Sardinian autoimmune polyendocrinopathy-candidiasis-ectodermal dystrophy patients. Hum Genet 103: 428-434

144. Maes M, Eisenbarth GS (1999) The polyglandular autoimmune syndromes. In: Volpé R (ed) Contemporary Endocrinology on Autoimmune Endocrinopathies, Humana Press Inc, Totowa, pp 349-363

145. Ward L, Paquette J, Seidman E et al. (1999) Severe autoimmune polyendocrinopathy-candidiasis-ectodermal dystrophy in an adolescent girl with a novel AIRE mutation: response to immunosuppressive therapy. J Clin Endocrinol Metab 84: 844-852

146. Gylling M, Tuomi T, Bjorses P et al. (2000) ss-Cell Autoantibodies, Human Leukocyte Antigen II Alleles, and Type 1 Diabetes in Autoimmune PolyendocrinopathyCandidiasis-Ectodermal Dystrophy. J Clin Endocrinol Metab 85: 4434-4440

147. Husebye ES, Gebre-Medhin G, Tuomi T et al. (1997) Autoantibodies against aromatic L-amino acid decarboxylase in autoimmune polyendocrine syndrome type I. J Clin Endocrinol Metab 82: 147-150

148. Aaltonen J, Björses P, Perheentupa J et al. (1997) An autoimmune disease, APECED, caused by mutations in a novel gene featuring two PHD-type zinc-finger domains. Nat Genet 17: 399-403

149. Nagamine K, Peterson P, Scott HS et al. (1997) Positional cloning of the APECED gene. Nat Genet 17: 393-398

150. Scott HS, Heino M, Peterson P et al. (1998) Common mutations in autoimmune polyendocrinopathy-candidiasisectodermal dystrophy patients of different origins. Mol Endocrinol 12: 1112-1119

151. Heino M, Scott HS, Chen Q et al. (1999) Mutation analyses of North American APS-1 patients. Hum Mutat 13: 69-74

152. Pearce SH, Cheetham T, Imrie H et al. (1998) A common and recurrent 13-bp deletion in the autoimmune regulator gene in British kindreds with autoimmune polyendocrinopathy type 1. Am J Hum Genet 63: 1675-1684

153. Saugier-Veber P, Drouot N, Wolf LM, Kuhn JM, Frebourg $\mathrm{T}$, Lefebvre $\mathrm{H}$ (2001) Identification of a novel mutation in the autoimmune regulator (AIRE-1) gene in a French family with autoimmune polyendocrinopathy-candidiasisectodermal dystrophy. Eur J Endocrinol 144: 347-351

154. Pitkanen J, Doucas V, Sternsdorf T et al. (2000) The autoimmune regulator protein has transcriptional transactivating properties and interacts with the common coactivator CREB-binding protein. $\mathrm{J}$ Biol Chem 275: 16802-16809

155. Rinderle C, Christensen HM, Schweiger S, Lehrach H, Yaspo ML (1999) AIRE encodes a nuclear protein co-localizing with cytoskeletal filaments: altered sub-cellular distribution of mutants lacking the PHD zinc fingers. Hum Mol Genet 8: 277-290

156. Bjorses P, Halonen M, Palvimo JJ et al. (2000) Mutations in the AIRE gene: effects on subcellular location and transactivation function of the autoimmune polyendocri- 
nopathy-candidiasis-ectodermal dystrophy protein. Am J Hum Genet 66: 378-392

157. Heino M, Peterson P, Kudoh J et al. (1999) Autoimmune regulator is expressed in the cells regulating immune tolerance in thymus medulla. Biochem Biophys Res Commun 257: 821-825

158. Halonen M, Pelto-Huikko M, Eskelin P, Peltonen L, Ulmanen I, Kolmer M (2001) Subcellular location and expression pattern of autoimmune regulator (Aire), the mouse orthologue for human gene defective in autoimmune polyendocrinopathy candidiasis ectodermal dystrophy (APECED). J Histochem Cytochem 49: 197-208

159. Ruan QG, Wang CY, Shi JD, She JX (1999) Expression and alternative splicing of the mouse autoimmune regulator gene (Aire). J Autoimmun 13: 307-313

160. Bjorses P, Pelto-Huikko M, Kaukonen J, Aaltonen J, Peltonen L, Ulmanen I (1999) Localization of the APECED protein in distinct nuclear structures. Hum Mol Genet 8: 259-266

161. Wang CY, Shi JD, Davoodi-Semiromi A, She JX (1999) Cloning of Aire, the mouse homologue of the autoimmune regulator (AIRE) gene responsible for autoimmune polyglandular syndrome type 1 (ASP1). Genomics 55: 322-326

162. Mittaz L, Rossier C, Heino M et al. (1999) Isolation and characterization of the mouse Aire gene. Biochem Biophys Res Commun 255: 483-490

163. Shi JD, Wang CY, Marron MP et al. (1999) Chromosomal localization and complete genomic sequence of the murine autoimmune regulator gene (Aire). Autoimmunity 31: 47-53

164. Heino M, Peterson P, Sillanpaa N et al. (2000) RNA and protein expression of the murine autoimmune regulator gene (Aire) in normal, RelB-deficient and in NOD mouse. Eur J Immunol 30: 1884-1893

165. Zuklys S, Balciunaite G, Agarwal A, Fasler-Kan E, Palmer E, Hollander GA (2000) Normal thymic architecture and negative selection are associated with Aire expression, the gene defective in the autoimmune-polyendocrinopathy-candidiasis-ectodermal dystrophy (APECED). J Immunol 165: 1976-1983

166. Vaidya B, Imrie H, Geatch DR et al. (2000) Association analysis of the cytotoxic T lymphocyte antigen-4 (CTLA4) and autoimmune regulator-1 (AIRE-1) genes in sporadic autoimmune Addison's disease. J Clin Endocrinol Metab 85: 688-691

167. Soderbergh A, Rorsman F, Halonen M et al. (2000) Autoantibodies against aromatic L-amino acid decarboxylase identifies a subgroup of patients with Addison's disease. J Clin Endocrinol Metab 85: 460-463

168. Ishii T, Suzuki Y, Ando N, Matsuo N, Ogata T (2000) Novel mutations of the autoimmune regulator gene in two siblings with autoimmune polyendocrinopathy-candidiasis-ectodermal dystrophy. J Clin Endocrinol Metab 85: 2922-2926

169. Nithiyananthan R, Heward JM, Allahabadia A, Barnett AH, Franklyn JA, Gough SC (2000) A heterozygous deletion of the autoimmune regulator (AIRE1) gene, autoimmune thyroid disease, and type 1 diabetes: no evidence for association. J Clin Endocrinol Metab 85: 1320-1322

170. Meyer G, Donner H, Herwig J, Bohles H, Usadel KH, Badenhoop K (2001) Screening for an AIRE-1 mutation in patients with Addison's disease, type 1 diabetes, Graves' disease and Hashimoto's thyroiditis as well as in APECED syndrome. Clin Endocrinol (Oxf) 54: 335-338

171. Maclaren N, Chen Q, Kukreja A, Marker J, Zhang CH, Sun ZS (2001) Autoimmune hypogonadism as part of an autoimmune polyglandular syndrome. J Soc Gynecol Investig 8: S52-S54

172. Powell BR, Buist NR, Stenzel P (1982) An X-linked syndrome of diarrhea, polyendocrinopathy, and fatal infection in infancy. J Pediatr 100: 731-737

173. Chatila TA, Blaeser F, Ho N et al. (2000) JM2, encoding a fork head-related protein, is mutated in X-linked autoimmunity-allergic disregulation syndrome. Clin Invest 106: R75-R81

174. Patel DD (2001) Escape from tolerance in the human Xlinked autoimmunity-allergic disregulation syndrome and the Scurfy mouse. J Clin Invest 107: 155-157

175. Bennett CL, Yoshioka R, Kiyosawa H et al. (2000) XLinked syndrome of polyendocrinopathy, immune dysfunction, and diarrhea maps to Xp11.23-Xq13.3. Am J Hum Genet 66: 461-468

176. Bennett CL, Christie J, Ramsdell F et al. (2001) The immune dysregulation, polyendocrinopathy, enteropathy, $\mathrm{X}$-linked syndrome (IPEX) is caused by mutations of FOXP3. Nat Genet 27: 20-21

177. Ferguson PJ, Blanton SH, Saulsbury FT et al. (2000) Manifestations and linkage analysis in X-linked autoimmunity-immunodeficiency syndrome. Am J Med Genet 90: 390-397

178. Lyon MF, Peters J, Glenister PH, Ball S, Wright E (1990) The scurfy mouse mutant has previously unrecognized hematological abnormalities and resembles Wiskott-Aldrich syndrome. Proc Natl Acad Sci USA 87: 2433-2437

179. Godfrey VL, Rouse BT, Wilkinson JE (1994) Transplantation of $\mathrm{T}$ cell-mediated, lymphoreticular disease from the scurfy (sf) mouse. Am J Pathol 145: 281-286

180. Baud O, Goulet O, Canioni D et al. (2001) Treatment of the immune dysregulation, polyendocrinopathy, enteropathy, X-linked syndrome (IPEX) by allogeneic bone marrow transplantation. N Engl J Med 344: 1758-1762 